INTERNATIONAL MONETARY FUND

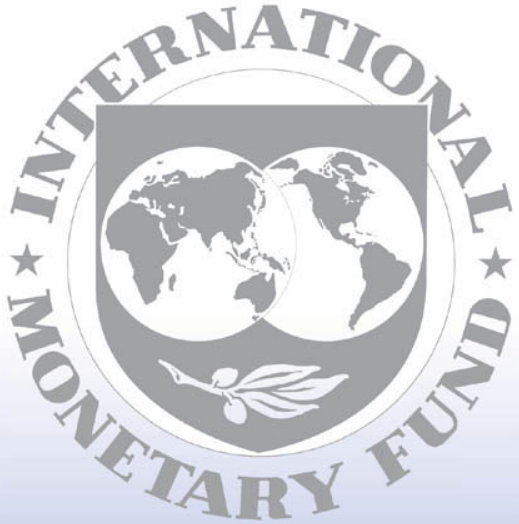

Staff

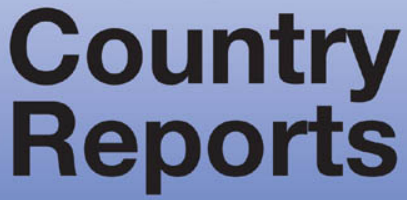




\section{Republic of Mozambique: Selected Issues}

This Selected Issues paper for the Republic of Mozambique was prepared by a staff team of the International Monetary Fund as background documentation for the periodic consultation with the member country. It is based on the information available at the time it was completed on June 1, 2007. The views expressed in this document are those of the staff team and do not necessarily reflect the views of the government of the Republic of Mozambique or the Executive Board of the IMF.

The policy of publication of staff reports and other documents by the IMF allows for the deletion of market-sensitive information.

To assist the IMF in evaluating the publication policy, reader comments are invited and may be sent by e-mail to publicationpolicy@imf.org.

Copies of this report are available to the public from

International Monetary Fund • Publication Services

700 19th Street, N.W. • Washington, D.C. 20431

Telephone: (202) $6237430 \bullet$ Telefax: (202) 6237201

E-mail: publications@imf.org • Internet: http://www.imf.org

Price: $\$ 18.00$ a copy

International Monetary Fund

Washington, D.C. 
This page intentionally left blank

CInternational Monetary Fund. Not for Redistribution 


\section{INTERNATIONAL MONETARY FUND}

\section{REPUBLIC OF MOZAMBIQUE}

\section{Selected Issues}

Prepared by Victor Lledó, Shanaka J. Peiris (both AFR), and Eteri Kvintradze (PDR) Approved by the African Department

June 1,2007

Contents

Introduction. $\underline{4}$

I. Macroeconomic Management of Scaled-up Foreign Aid in Mozambique . .5

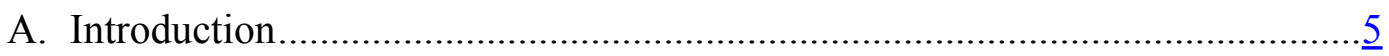

B. Foreign Aid and Macroeconomic Management in Mozambique ....................... $\underline{6}$

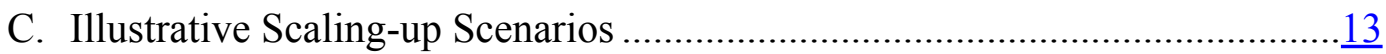

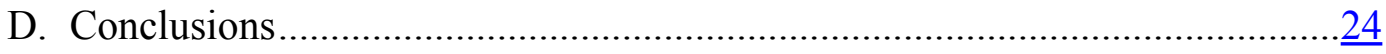

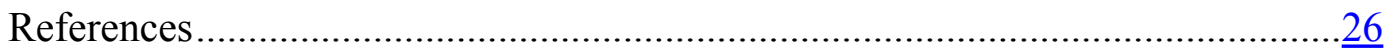

II. Evaluating Mozambique's Financial Sector Reform Strategy …………............28
A. Introduction. .$\underline{28}$
B. Diagnosing Mozambique's Financial Sector ................................................
C. Mozambique's Financial Sector Reform Strategy ………………………....

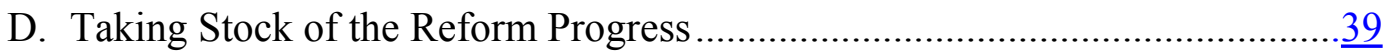
E. Strengthening the Strategy: Lessons and Challenges ......................................46

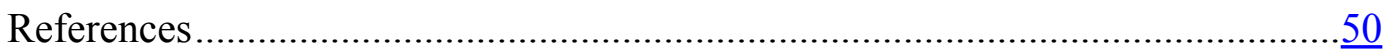

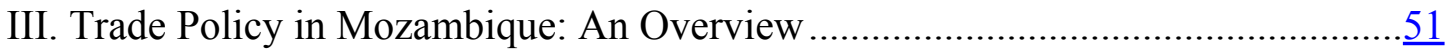
A. Introduction.
B. Trade Policy Options

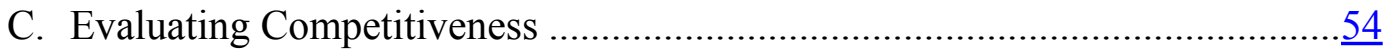

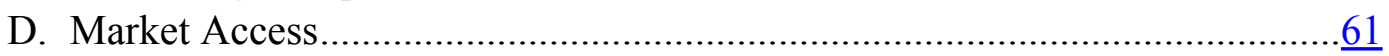
E. Conclusion: Policy Priorities and Lessons.......................................................64

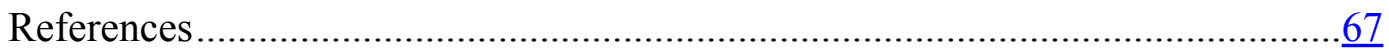


Text Boxes

I.1. PFM Reforms in Mozambique.................................................................

II.1. Institutional Roots of Poor Financial Intermediation in Mozambique ..............

II.2. Weaknesses in Monetary Policy Management .............................................. $\frac{32}{34}$

II.3. Summary of Key FSAP Recommendations ................................................

II.4. Key Elements of the Reform Strategy: FSTAP Components ………………...37

II.5. IMF Technical Assistance Strategy …………............................................

II.6. Strengthening Banking Supervision and Regulatory Environment

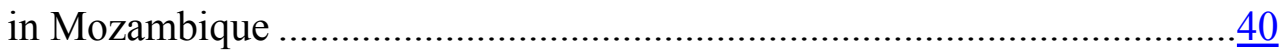

II.7. Strengthening Monetary and Public Debt Management in Mozambique......... $\underline{42}$

II.8. Strengthening Mozambique's Lending Environment.....................................43

II.9. Microfinance in Mozambique...................................................................

Text Figures

I.1. Fiscal Effects of Foreign Aid .....................................................................

I.2. Fiscal Effects of Foreign Aid (cont.) ……...............................................

I.3. Macroeconomic Impact of Foreign Aid.................................................... 12

I.4. Macroeconomic Impact of Foreign Aid (cont.) …........................................12

I.5. Scaling-up Scenarios........................................................................... 15

I.6. Mozambique and Comparators: Total TFP Decomposition ………………....17

I.7. Fiscal Framework under an Annual US\$200 million Scaling-up of Externally Borrowed Expenditures ........................................................................

II.1. Decomposition of Interest Rates Spreads in Meticais ....................................29

II.2. Bank Soundness Evolution, 2000-06 .................................................. $\frac{43}{43}$

II.3. Financial Intermediation Evolution, 2000-06 ........................................... $\frac{43}{54}$

III.1. Analytical Framework: Trade Policy Choices............................................54

III.2. Megaprojects Share in Total Exports and Imports .......................................

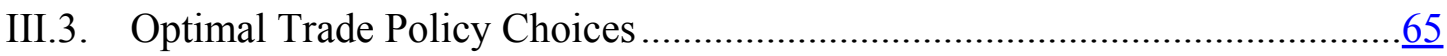

Text Tables

I.1. Increasing Returns to Public Investment: Lessons From Asia ……….............16

II.1. Mozambique and Comparators: Financial Intermediation, 2002 ....................29

II.2. Mozambique and Comparators: Savings Mobilization,

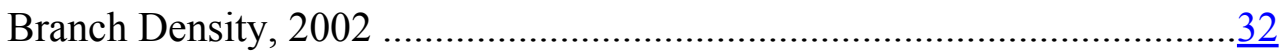

II.3. FSTAP Support by Components and Agencies ...........................................

II.4. Developments in Perceived Constraints ......................................................44

III.1. Share in World's Exports and Terms of Trade ............................................ $\frac{55}{55}$

III.2. Export Profile........................................................................

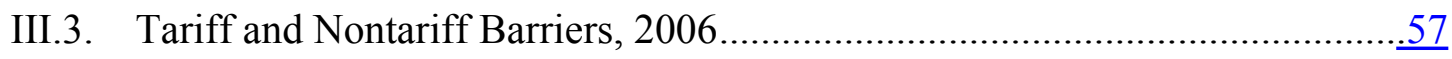

III.4. Average Tariff, 2006 ...................................................................... $\frac{58}{58}$

III.5. Types of Nontariff Barriers and Ratings, 2006........................................... $\frac{58}{59}$

III.6. Share of Exports and Imports (percent of GDP) ......................................... 
III.7. Results of Firm-Level Survey

III.8. Mozambique and Comparators: Distance to Top Rank in Business

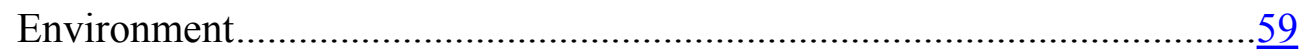

III.9. Cost of Doing Business Rankings, 2006 data...............................................60

III.10. Mirror Statistics on Trade with Bordering Countries, 2004 ……....................61

III.11. Destination of Exports ...........................................................................

III.12. Actual and Estimated Revenue from International Trade, 2004 ......................63

III.13. Labor Cost for Garments, Business Environment and

Market Access for Selected Countries..........................................................64

Appendices

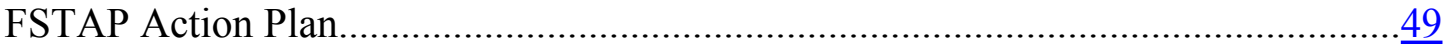

Regional Trade Agreements: Organizational Integrity............................................ 


\section{INTRODUCTION}

The following chapters discuss key policy and institutional issues in the macroeconomic management of scaled-up aid and in promoting sustainable private-sector led growth through the design and implementation of effective financial sector and trade reform strategiesareas identified as essential conditions for macroeconomic stability, sustainable growth, and thus core to the IMF mandate.

- Chapter I examines the macroeconomic challenges of managing scaled-up foreign aid in Mozambique. In particular, it discusses key measures and policies that would help absorb and efficiently use aid. It concludes that a further moderate scaling-up of foreign aid could continue to be fully spent and focus on productive priority sectors. This would help achieve the Millennium Development Goals while at the same time eliciting a supply response to mitigate potential Dutch-disease effects brought by an appreciating real exchange rate. As such, the chapter emphasizes the importance of prioritizing productive government investments and accelerating the implementation of second-generation reforms, including strengthening agricultural productivity, the business environment and public financial management systems.

- Chapter II evaluates Mozambique's financial sector reform strategy, particularly its record in promoting financial sector development. It argues that Mozambique's financial sector strategy has prioritized macroprudential measures to restructure an ailing banking sector and to restore the soundness of the financial system as a pre-requisite to mitigate the impact of credit risk and macroeconomic volatility on financial sector intermediation. It notes that Mozambique's financial sector strategy, besides being well sequenced, has novel implementation features that have encouraged greater donor coordination without compromising ownership or adding excessive transaction costs. However, access to affordable finance is still recognized as the main obstacle to private sector development. As such, improving financial sector development will require accelerating reforms to strengthen the institutional lending environment and facilitating the outreach of privately provided financial services to small and medium-sized enterprises and rural areas.

- Chapter III uses a simple qualitative framework to summarize and discuss Mozambique's trade policy options. It notes that Mozambique has a less restrictive trade regime than most sub-Saharan African countries, and already enjoys preferential access to profitable markets. However, Mozambique's business environment is shown to be weak by regional standards, with burdensome and ineffective trade regulations among its most binding constraints. In this context, the chapter concludes that streamlining Mozambique's business environment should be given priority. This policy is shown to not only improve competitiveness directly by reducing the costs of doing business, but also to have important indirect effects by allowing unilateral trade liberalization to effectively improve firm-level competitiveness, and market access opportunities to be securely tapped. 


\section{Macroeconomic Management of SCALEd-up Foreign Aid in Mozambique ${ }^{1}$}

\section{A. Introduction}

\section{While large aid inflows can play an important role in achieving the Millennium} Development Goals (MDGs), they also pose a number of macroeconomic challenges. The Commission for Africa (2005) and the U.N. Millennium Project identifies the need for a scaling-up of aid flows to meet the MDGs in well-governed low-income countries, including Mozambique. Scaling-up scenarios are intended to illustrate a potential medium-to-long-term macroeconomic outcome, and identify some of the key measures and policies that would help countries absorb a higher level of aid and ensure that it is used efficiently. In practice, donors might be less likely to offer higher aid and recipient governments might be less likely to accept it on a sustained basis if one party or the other started to observe significant macroeconomic absorption problems - such as rising inflation, crowding-out the private sector and/or a serious loss of international competitiveness, and microeconomic capacity constraints - severe skill shortages, deteriorating quality of services or other bottlenecks. Such scaling-up scenarios are developed in the context of a country's efforts to achieve the MDGs with the support of the international donor community. ${ }^{2}$

\section{There are three basic approaches to preparing scaling-up scenarios (IMF 2006).}

The first approach assesses the macroeconomic implications of a fiscal scenario that is based on an explicit costing of achieving those MDGs that do not focus on income levels (e.g., those related to education, health, and water access). The costing exercise, which is typically carried out with the assistance from development partners such as the World Bank and the U.N., provides a judgment about the resources required in each sector. It also may illustrate trade-offs among policies, resources, macroeconomic outcomes, and identify bottlenecks that need to be addressed. A second approach is to assess the macroeconomic impact of a significant but arbitrary increase of external finance (e.g., 1-2 percent of GDP or a doubling of aid). This approach is probably more suited for Mozambique as an explicit MDG costing is not yet available and aid inflows continue to be large and rising (about 15 percent of GDP). A third approach is to target a specific growth rate if achieving the income poverty MDG is unrealistic with present resources and policies, which is not the case in Mozambique. $^{3}$

\footnotetext{
${ }^{1}$ Prepared by Shanaka J. Peiris.

${ }^{2}$ Mozambique's new PRSP or Plano de Acção para Redução da Pobreza Absoluta II(PARPA II) for 2006-09 considers a modest increase in external financing including the MDRI and could be complemented with more detailed scaling-up scenarios in annual progress reports.
}

${ }^{3}$ See Fox et al., (2007) for the likelihood of achieving the income poverty MDG in Mozambique. 
3. The objective of this paper is to assess the macroeconomic challenges of managing scaled-up foreign aid in Mozambique. The paper is organized as follows: section B analyses the past impact of aid in Mozambique; section C presents illustrative scaling-up scenarios geared to identifying macroeconomic policy tradeoffs and improving potential outcomes; and section D concludes by identifying the challenges for Mozambique.

\section{B. Foreign Aid and Macroeconomic Management in Mozambique}

\section{Identifying the fiscal effects of aid is a prerequisite to understanding the} macroeconomic impact of aid (McGillivray and Morrissey 2001). However, there has been limited analysis of the fiscal effects of aid in Mozambique. ${ }^{4}$ Therefore, we will start by estimating the fiscal impact of aid in Mozambique.

\section{There is a growing literature on how aid affects the fiscal behavior of} governments (see McGillivray and Morrissey 2001). The most common approach is through fiscal response models (FRMs). These studies tend to find that aid ultimately leads to increased spending, and total spending often increases by more than the value of aid (McGillivray and Morrissey 2001). There is evidence that aid has had a beneficial impact on investment and recurrent spending in sub-Saharan African countries (Commission for Africa 2005). IMF (2005a) suggests that aid was mostly spent in Mozambique where the degree of spending was calculated by the widening in the government fiscal deficit net of aid that accompanies an increase in aid. ${ }^{5}$ IMF (2005a) shows that public expenditures actually increased, on average, more than the increment in net aid inflows, leading to a substantial widening of the fiscal deficit net of aid during the aid surge of 2000-02. The aid surge was roughly equally distributed between current and capital expenditures. However, IMF (2005a) focus on short time periods of surges in aid and relatively simplistic approach compared to the fiscal response literature of aid may miss more complicated dynamic effects (Mavrotas 2002).

6. The fiscal effects of aid in Mozambique are assessed by estimating a FRM within a vector autoregression (VAR) modeling framework as in Osei, Morrissey, and Lloyd (2005). The variables of the fiscal response VAR model are ordered as follows: foreign aid (AID), government expenditure (Expenditures), tax revenue (Tax), and the change in net credit to the government from the banking system (NCG). Note that as nontax components of revenue and nonbank borrowing are omitted, we are not estimating an identity. We also estimate a model in which foreign aid is divided by grants and loans as well as and project

\footnotetext{
${ }^{4}$ See Arndt et al., (2007) and World Bank (2005).

${ }^{5}$ The deficit net of aid is equal to total expenditures $(\mathrm{G})$ less domestic revenue $(\mathrm{T})$ and is financed by a combination of net aid and domestic financing: $G-T=$ Nonaid fiscal deficit $=$ Net aid + Domestic financing.
} 
aid and budget support (BUDSUP). Total government expenditure is disaggregated into capital and current components. We use quarterly data over the period 1996Q1 to 2006Q3 with all the variables measured in constant 2004 prices expressed in millions of new meticais (MT). Data on domestic fiscal variables and external financing are obtained from IMF country desk data.

\section{The dynamic effects of aid shocks can be evaluated using impulse response}

functions. An analysis of the time-series properties of the variables revealed that the variables are integrated of order one or I(1), except for aid and NCG which are stationary $\mathrm{I}(0)$. However, cointegration tests did not identify a significant cointegrating vector between the variables. Therefore, the series are first differenced for estimation purposes to avoid the spurious and inconsistent regression problem (Hendry 1995). ${ }^{6}$ Results of Granger causality tests are somewhat mixed, but clearly point to aid Granger-causing fiscal variables but not vice versa. This suggests that aid disbursements have not been influenced by the budget balance over the period. In addition, this tends to suggest that shocks to foreign aid are exogenous to the system rather than determined by it and offers statistical support for the legitimacy of the impulse response analysis of aid shocks in Mozambique below. The structural shocks are recovered from the VAR residuals using the Cholesky decomposition of the variance-covariance matrix. ${ }^{7}$

8. Aid has been mostly spent in Mozambique. Plots of the impulse response functions for a one standard deviation shock in aid on a quarterly time interval are shown in Figures 1-2. A one standard deviation shock corresponds to about MT 1500 million (this would represent about 1 percent of GDP in 2004). Figure 1 with total aid and expenditures shows that the cumulative impulse response to an aid shock of one standard deviation gives a full pass-through (change in spending $t$ periods after the shock over an initial percent change in aid) within four quarters. In fact, as observed in IMF (2005a), public expenditures actually have a tendency to increase more than the original shock to aid in Mozambique. However, unlike IMF (2005a), the aid shock seems to result in more capital expenditures with only about one-third of the aid financing current spending within a year (Figure 2). ${ }^{8}$ Not only does

\footnotetext{
${ }^{6}$ The VARs were also estimated using detrended data. The results were largely unchanged from that of firstdifferencing the data, and thus are not reported here.

${ }^{7}$ The Cholesky decomposition imposes the correct number of restrictions for just identification and imposes a recursive structure on the system; so that the most endogenous variable is ordered last, that is it is affected by all contemporaneous "structural" shocks.

${ }^{8}$ It should be noted, however, that all donor-financed projects are classified as capital spending in the fiscal accounts although a significant share of such spending is likely on wages and goods and services. In addition, the unavailability of expenditures on a quarterly basis according to a functional classification also limits an analysis of the impact of foreign aid on the composition of spending.
} 
aid result in an increase in capital spending, but it leads to an increase in domestic taxation. Moreover, these results are largely unaltered whether one considers loans or grants, ${ }^{9}$ although the picture is somewhat less clear regarding the impact of aid on NCG possibly reflecting smoothing of expenditures and/or issuance of domestic debt. However, as expected, budget support seems to initially reduce NCG and start picking up with a slight lag of a quarter or two but still leading to a full spending within 5-6 quarters.

Figure I.1. Fiscal Effects of Foreign Aid
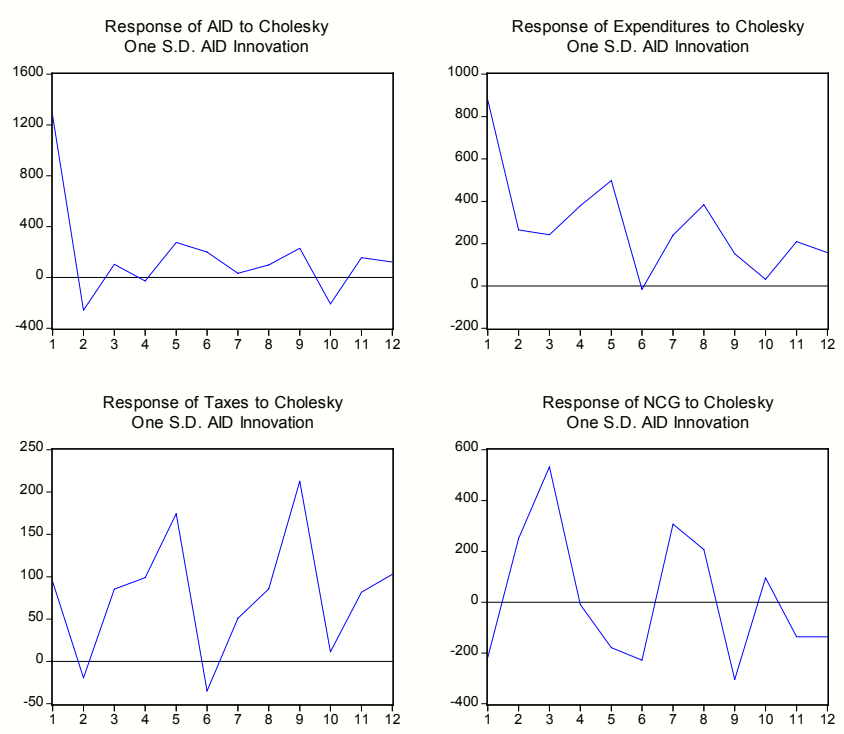

\footnotetext{
${ }^{9}$ The increase in government taxation allays concerns identified in Gupta et al. 2004 that grants can substitute for domestic revenues, and, hence, are more likely to dampen domestic efforts to collect more revenue.
} 
Figure I.2.Fiscal Effects of Foreign Aid (cont.)
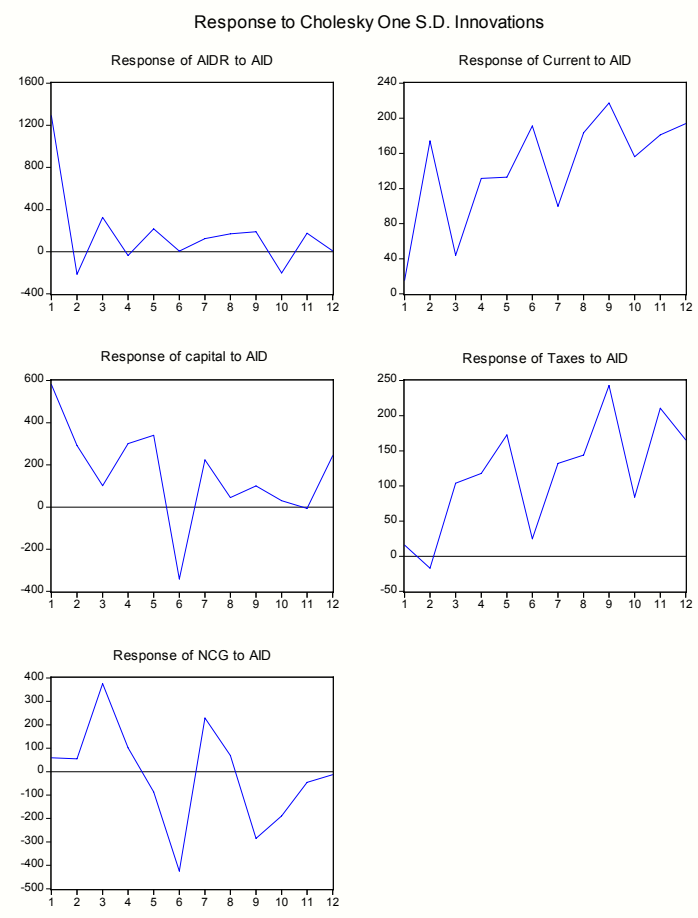

9. The spending of foreign aid could undermine competitiveness, although such effects can be ameliorated depending on the nature of the supply side response over the long-term. Given that aid inflows have been spent by the government in Mozambique, the next issue is whether these expenditures have induced a significant appreciation of the real exchange rate and thus discouraged the expansion of exports, thereby hurting long-term growth. The results presented in the staff report show that government spending (both current and total expenditures) has tended to appreciate the fundamental equilibrium real exchange rate but some of those effects have been mitigated by trade liberalization and negative terms of trade movements. ${ }^{10}$ In addition, even though Mozambique's total export shares in world trade have increased this is mainly as a result of the strong growth in megaproject exports. Nonmegaproject exports share of world trade and ratio to GDP has remained roughly constant. As such, concerns remain regarding the impact of scaled-up aid on Mozambique's competitiveness. These results are somewhat different from those presented in BenitoSpinetto and Moll (2005) who simulate a simple 1-2-3 model in the spirit of Devarajan et al.

\footnotetext{
${ }^{10}$ Another issue frequently discussed in the literature is the degree of REER misalignment. Econometric results presented in the staff report, suggest that the REER may have potentially been overvalued at times of tight exchange rate management. As a result, export performance may be weaker than it could have been if the REER had been aligned with its underlying equilibrium rate. However, it is difficult to infer whether such deviations from equilibrium could be attributed to the response to aid in Mozambique.
} 
(1994) and indicate that Dutch disease appears not to be an important factor in Mozambique. They argue that supply-side effects of aid coming through health and infrastructure investments could help mitigate a real exchange rate appreciation. The lack of visible evidence that supply-side effects are strong enough to dampen pressures on the real exchange rate to appreciate due to the demand side impact of spending the aid inflow may, however, be explained by well-known lagged (and possibly nonlinear) effects as well as the rudimentary state of PFM systems in Mozambique, that, at least until recently, were relatively weak compared to most other SSA countries. ${ }^{11}$

\section{Even the short-run response to aid is dependent on a number of factors,} including the degree of aid absorption. ${ }^{12}$ As discussed in Peiris and Saxegaard (2007), the impulse responses of the estimated DSGE model for Mozambique shows that the degree of absorption of aid-financed spending can have very different effects on the short-term dynamics of the exchange rate, output and inflation. In order to investigate how those effects may have played out in Mozambique, we estimate an identified six-variable VAR from Q1 1996 to Q3 2006. ${ }^{13}$ The ordering of the variables embodies two key identifying assumptions, that is, that aid shocks contemporaneously effects all variables in the system and that economic variables do not respond contemporaneously to the policy variables, except for the exchange rate. The exchange rate is an asset price, and is expected to response faster to policy shocks than real economy variables. The following ordering is chosen: foreign aid, real $\mathrm{GDP}^{14}$ (or real nonmegaproject exports), inflation, reserves, domestic debt, and the nominal exchange rate. The structural shocks are recovered from the VAR residuals using the Cholesky decomposition of the variance-covariance matrix. While the ordering is certainly debatable and a nonrecursive structural VAR could have been used for identification, the estimation provides a generalized view of the impact of aid shocks in Mozambique. In addition, it is fairly well accepted that many macroeconomic variables do

\footnotetext{
${ }^{11}$ See IMF (2005b) for a comparison of PFM systems undertaken for highly indebted poor countries.

${ }^{12}$ IMF (2005a) defines aid absorption as the extent to which a country's nonaid current account deficit (in foreign currency terms) widens in response to an increase in aid inflows. If one assumes that the capital account is closed as in Peiris and Saxegaard (2007), full aid absorption is equivalent to an unchanged level of international reserves in response to an aid shock. This latter definition is used in this chapter.
}

${ }^{13}$ An analysis of the time-series properties of the variables revealed that the variables are integrated of order one or I(1), except for aid which is stationary $\mathrm{I}(0)$. Therefore, the series are detrended for estimation purposes to avoid the spurious and inconsistent regression problem (Hendry 1995). Results of Granger causality tests are somewhat inconclusive, showing little evidence of Granger causality in either direction, but lend support for a transmission of aid shocks to the domestic economy.

\footnotetext{
${ }^{14}$ Quarterly GDP series are yet unavailable in Mozambique, therefore a quarterly GDP proxy was constructed statistically by estimating the correlates of real GDP annually and using predictions based on the quarterly explanatory variables.
} 
not respond instantaneously to policy shocks, particularly when we consider quarterly time intervals (see Christiano et al., 2005 for the general approach).

\section{Aid-financed expenditures have been mostly absorbed in Mozambique, with} only hints of Dutch-disease effects affecting the export sector (Figures 3 and 4). The impulse responses on a quarterly time interval suggests that aid shocks (that have been mostly spent) have, at least initially, resulted in a nominal exchange rate appreciation, and possibly lower output. Inflation declines initially but picks up gradually. A similar picture emerges when one considers real nonmegaproject exports instead of our proxy for real GDP, suggesting only modest contractions of the export sector in response to aid shocks in Mozambique. Interesting, most of the foreign exchange associated with aid inflows appears to have been sold by the central bank within five quarters of the initial aid shock facilitating a textbook spend and absorb response to aid in Mozambique. The results do indicate, however, that the central bank may have somewhat smoothed sales of foreign exchange sales in the very short term through temporary net domestic debt issuance (i.e., sterilization) possibly to avoid "excessive" exchange rate volatility in a thin market. The temporary mopping-up of excess liquidity through sterilization while ultimately selling the foreign exchange may have helped keep prices at bay and minimized the likelihood of crowding-out private sector credit at the same time. This contrasts with the response to aid shocks of most other non-CFA SSA countries that seem to have relied more heavily on sterilization (IMF 2005a), contributing to unfavorable debt dynamics and probably greater crowding-out of the private sector. Overall, the macroeconomic impact of aid shocks seems to go roughly in the same direction as the model simulations for Mozambique in Peiris and Saxegaard (2007), in the case where aid has been absorbed through sales of foreign exchange by the central bank. 
Figure I. 3. Macroeconomic Impact of Foreign Aid

Response to Cholesky One S.D. Innovations \pm 2 S.E.
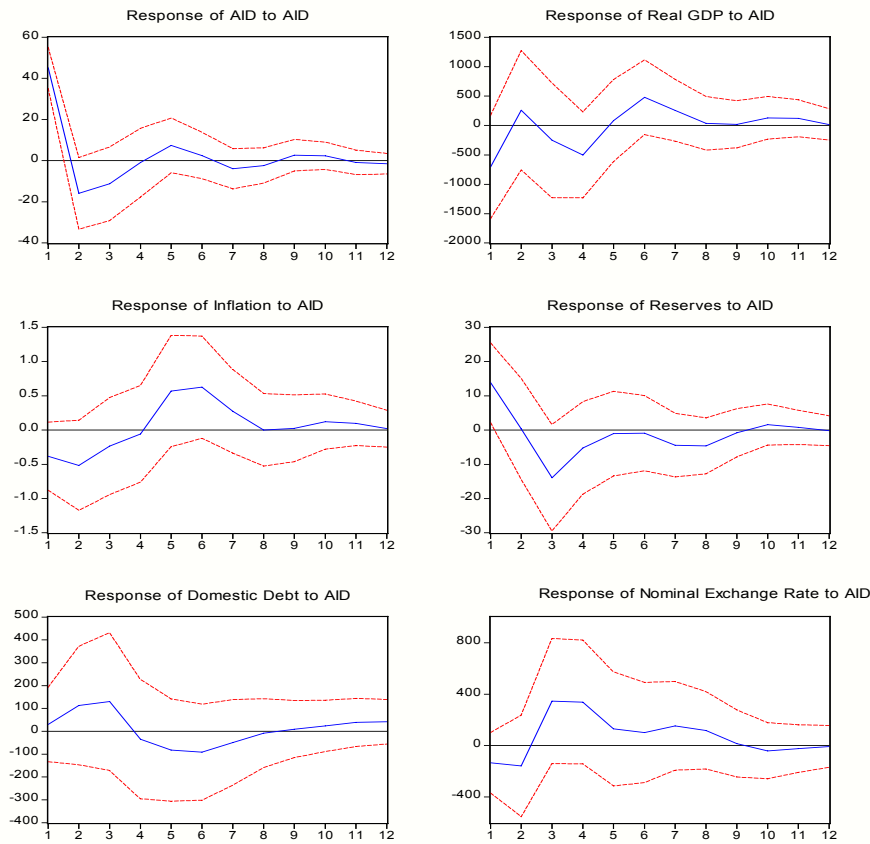

Figure I.4. Macroeconomic Impact of Foreign Aid (cont.)

Response to Cholesky One S.D. Innovations \pm 2 S.E.
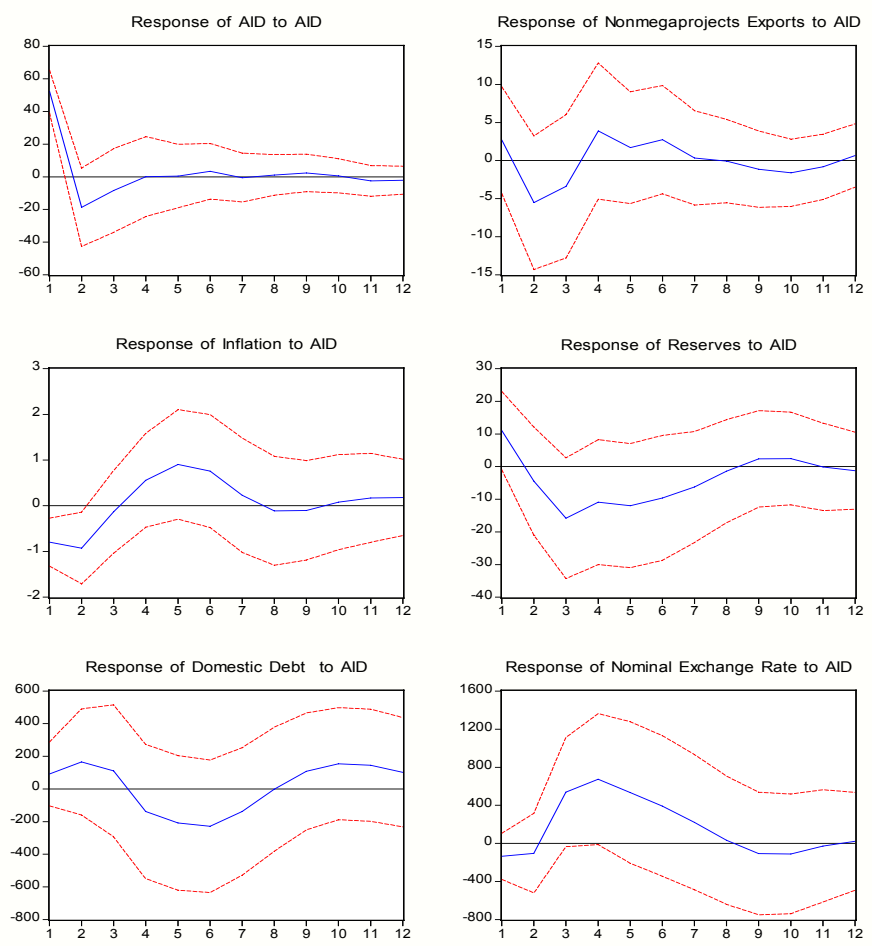


\section{Illustrative Scaling-up Scenarios}

\section{The purpose of illustrative scaling-up scenarios for Mozambique are to identify} the potential macroeconomic implications, and key measures and policies that would help absorb a higher level of aid and ensure that it is used efficiently. A full costing of the MDGs has not been undertaken for Mozambique and it appears to be well-placed to achieve the income poverty MDG by 2015 with present resources and policies. ${ }^{15}$ Therefore, we consider the macroeconomic consequences of arbitrary but sustained increases of external finance for illustrative purposes. This contrasts with scaling-up scenarios presented for a few other countries (e.g., Mattina 2006) based a costing of MDGs and targeting a specific growth rate to meet the income poverty MDG. The focus of this paper is more to discuss the macroeconomic implications and policy trade-offs involved in spending and absorbing a further scaling-up of foreign aid amounting to more than 15 percent of GDP at present.

\section{Macroeconomic implications and policy trade-offs}

\section{The impact on medium-to-long-term growth of a further scaling-up of aid is} difficult to gauge but research points to areas for further analysis and prioritization of reform strategies. A number of research papers that have undertaken growth accounting exercises for Mozambique (e.g., Jones 2007, IMF 2005c, and World Bank 2005) suggest that physical capital accumulation and total factor productivity have played a fundamental role in explaining the post-conflict growth acceleration supported by first-generation structural reforms. ${ }^{16}$ They also confirm the possibility of achieving about 7 percent growth in the medium term (baseline in staff report) and 5-6 percent in the long-term, a level sufficient to halve the poverty rate by 2015 , assuming a continuation of strong productivity growth given the relatively low productivity levels in agriculture and manufacturing (Fox et al., 2007, and Eifert, Gelb and Ramachandran 2005). On the specific issue regarding the impact of scalingup, Jones (2007) highlights the upside potential from higher public investment (depending on the ratio of current-to-capital spending), and crowding-in private investment and spillovers from infrastructure and human capital accumulation. Whilst formal modeling of absorptive capacity is in its infancy (for a discussion see Bourguignon and Sundberg, 2006), a preliminary estimation in Jones (2007) also shows possible negative consequences from a further scaling-up in Mozambique operating through private investment and human capital quality growth. The former is intended to reflect diminishing returns while the latter reflects labor market effects including the challenge for Mozambique of maintaining education quality in the face of rapid aid-financed expansion of the school network (see Arndt et al., 2007). Recent evidence suggest that primary education completion rates and the quality

\footnotetext{
${ }^{15}$ See Fox et al., (2007) for Mozambique's chances of halving the poverty rate by 2015.

${ }^{16}$ Jones (2007) also shows that advances in education have contributed significantly to Mozambique's growth.
} 
of education are relatively low, probably reflecting high pupil-to-teacher ratios and a growing number of untrained teachers, although innovate steps have been taken lately to address the shortage of trained teachers. ${ }^{17}$

\section{The literature and evidence presented in section $\mathbf{B}$ calls for paying particular} attention to potential Dutch-disease effects related to aid-financed scaling-up of expenditures and thus ways to mitigate such effects. While it is fairly well accepted that to spend and absorb is likely to be the best response to an aid shock in normal circumstances (see Buffie et al 2007, IMF 2005a, and Peiris and Saxegaard 2007), such a response could still entail a significant loss of competitiveness, and thus lower exports and real GDP growth. Therefore, we analyze this issue further by simulating the estimated DSGE model for Mozambique in Peiris and Saxegaard (2007) in response to a persistent aid shock (autocorrelation coefficient of 0.7 ) which raises aid by 2 percent of steady-state GDP. ${ }^{18}$ For illustrative purposes, we consider three scenarios (Figure 5). In the first scenario, we assume there are no productivity spillovers from public investment. The second scenario assumes a modest level of spillovers (the baseline in Peiris and Saxegaard 2007). In the third scenario, we consider a high level of productivity spillovers from public investment. All scenarios assume a full spending and absorption of foreign aid; the usual assumption in scaling-up scenarios. Note that the function form as in Pratti and Tressel (2006) assumes that productivity is an increasing function of the size of public investment expenditure; so the higher levels of productivity could come from greater spillovers (e.g., related to infrastructure investments) or a decrease in the ratio of current-to-capital spending. ${ }^{19}$ The unbroken line describes a scenario where there are no productivity spillovers; the thick broken line assumes a modest level of spillovers; and the light broken line depicts a higher level of productivity spillovers from public investment in response to aid shocks (Figure 5).

\section{Greater productivity-enhancing public investment expenditure could ameliorate or even reverse Dutch-disease effects of additional government spending in}

Mozambique (Figure 5). The impulse responses in Figure 5 on a quarterly time interval clearly shows the role productive government investment expenditures can play to mitigate Dutch-disease effects of aid-financed government spending by reducing real exchange rate appreciation pressures and thus eliciting a stronger export performance. Moreover, consumption and output are unambiguously higher with greater productivity spillovers as expected while the pick-up in inflation following an initial decline (as in section B) would be milder. At this point, it is important to note that analysis of this kind come with a number of

\footnotetext{
${ }^{17}$ A similar situation prevails in the health sector, particularly with regard to human resource constraints.

${ }^{18}$ See Peiris and Saxegaard (2007) for the structure of the DSGE model, estimation, and steady-state calibration.

${ }^{19}$ The calibration of the DSGE model uses the ratio of current-to-capital spending estimated for Mozambique.
} 
caveats. For example, we assumed that productive government spending affects the transitional dynamics of the economy but not the steady-state for simplicity and tractability. While this makes sense when considering fairly persistent but stationary aid shocks as observed in the past in Mozambique (see section B), one could have also considered the impact of permanent increase in aid that could affect steady-state variables, which is a area for future research. ${ }^{20}$ Finally, it is important to note that none of the outcomes of productivity spillovers from public investment are assured and will depend critically on the composition of government expenditure and efficiency of public service delivery. However, the discussion emphasizes the importance of prioritizing productive government investments and accelerating the implementation of second-generation reforms in PARPA II to increase returns to investment:

Figure I.5. Scaling-up Scenarios
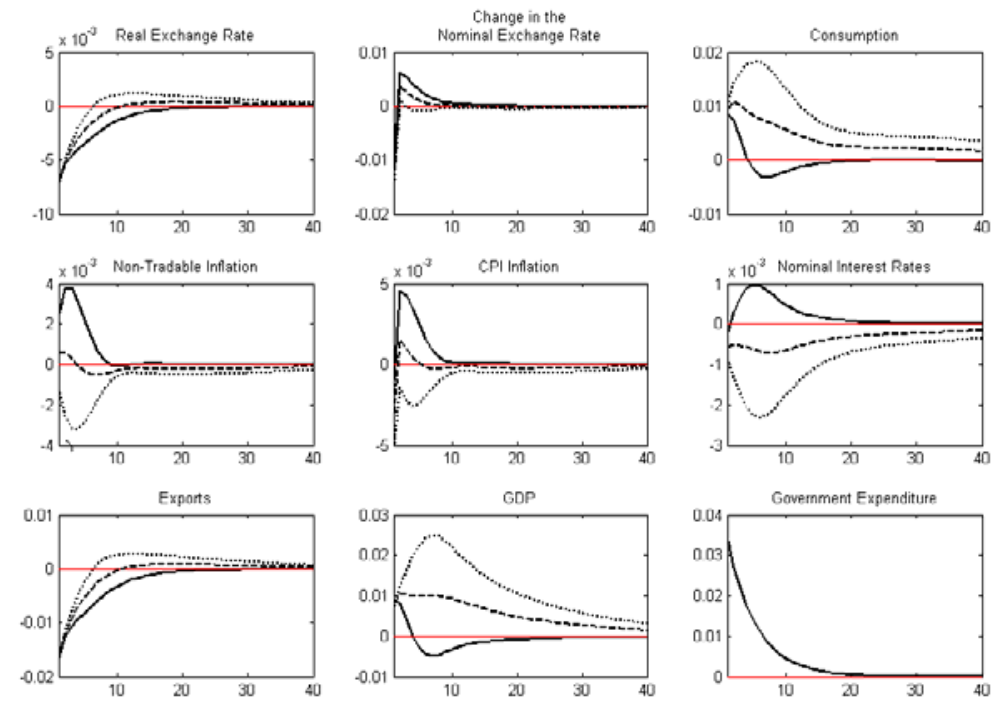

${ }^{20}$ Further analyses could also consider the impact of absorptive capacity, for example, through the World Bank's Marquette for MDG simulations as piloted on Ethiopia (see Mattina 2006). This is particularly true for Mozambique, as it is one of the few countries in the range of saturation points for aid identified in the literature. 
- Infrastructure and human capital accumulation. Since 2000, about 65 percent of scaled-up spending has been allocated to priority sectors (e.g., education, health and infrastructure) identified in Plano de Acção para Redução da Pobreza Absoluta I (PARPA I), helping double of the number of children in primary school, reduce in infant and maternal mortality, and begin the provision of Anti-Retro-Viral (ARV) treatment for HIV infection, partly financed by resources made available by the Highly Indebted Poor County (HIPC) initiative. While substantial progress has been made, large human capital and infrastructure gaps remain. Comparisons with fast growth Asian economies during the initial phases of their growth takeoff indicate the importance of expanding secondary education and addressing the acute infrastructure gap, particularly communication and transportation networks (Table 1).

\begin{tabular}{|c|c|c|c|c|}
\hline & Human & & Infrastructu & \\
\hline & Primary Education ${ }^{3}$ & $\begin{array}{r}\text { Secondary Education }{ }^{3} \\
\text { sub-Saharan }\end{array}$ & $\begin{array}{c}\text { Telephone Mainlines (per } \\
\text { 1,000 people) }\end{array}$ & $\begin{array}{l}\text { Total Roads Surface Area } \\
\text { (in km) }\end{array}$ \\
\hline Mozambique & 8 & 8. & 4 & 3 \\
\hline SADC & 10 & 42. & 6 & 227. \\
\hline SSA & 91. & 31. & 35. & 166. \\
\hline \multicolumn{5}{|c|}{ Selected Asian Countries that have sustained growth accelerations } \\
\hline Chin & 112. & 45. & 2 & 12 \\
\hline ASEAN 4 & 83. & 22. & 6. & 184. \\
\hline Indonesia & 8 & 16. & 1. & 151. \\
\hline Malaysi & 88. & 34. & 13. & 261. \\
\hline Thailan & 81. & 17. & 5. & 140. \\
\hline
\end{tabular}

Source: Johnson, Ostry and Subramanian (2007)

- Improving agricultural productivity lies at the heart of growth prospects and poverty reduction (Fox et al 2007). A great deal of the increase in crop income has been achieved through extensive agricultural practices, that is area expansion and use of available labor, both family and hired. As a result, basic food crops, widely grown by smallholder farmers, predominantly for subsistence, have exhibited relatively stagnant yields (output per hectare). Security of land-tenure and use of new technologies associated with cash crops mostly grown under contract by agro-industrial firms could help improve productivity. Smallholders can also increase land productivity and crop income through diversification into profitable cash crops many of which are tied to contract farming schemes. The use of productivity enhancing inputs (particularly fertilizers, seeds and irrigation), and developing rural credit and input markets can facilitate diversification to such crops. Further development of the agriculture sector would require the development of a good road infrastructure, storage facilities and extension services. Mozambique also has the potential to 
further cultivate high value vegetable crops and floriculture for export to Europe through better quality standards and marketing infrastructure. ${ }^{21}$

- $\quad$ Strengthening the business environment is key to building a manufacturing base and generating employment. While sustained growth accelerations tend to be associated with considerable manufacturing exports, Mozambique's manufacturing base remains nascent due to poor competitiveness. Low "factory-floor" productivity levels in manufacturing firms are explained by considerably high indirect costs and output losses including those from burdensome regulations as they squeeze firms value-added and reduce TFP, as well as the use of obsolete and ill-maintained equipment and the absence of modern management techniques. The wide gap in business competitiveness between Mozambique and fastgrowing Asian economies and regional competitors, as measured by the World Bank's Doing Business indicators, suggest that lowering the costs of doing business must be at the core of the authorities' reform strategy by: (i) streamlining burdensome regulatory practices;

(ii) reducing the costs of hiring and firing workers; (iii) removing infrastructure bottlenecks; (iv) a financial sector reform agenda centered on further reducing the cost of and expanding access to financial services; and (v) a governance agenda to minimize expropriation risks.

Figure I.6. Mozambique and Comparators: Total TFP Decomposition (China =1)

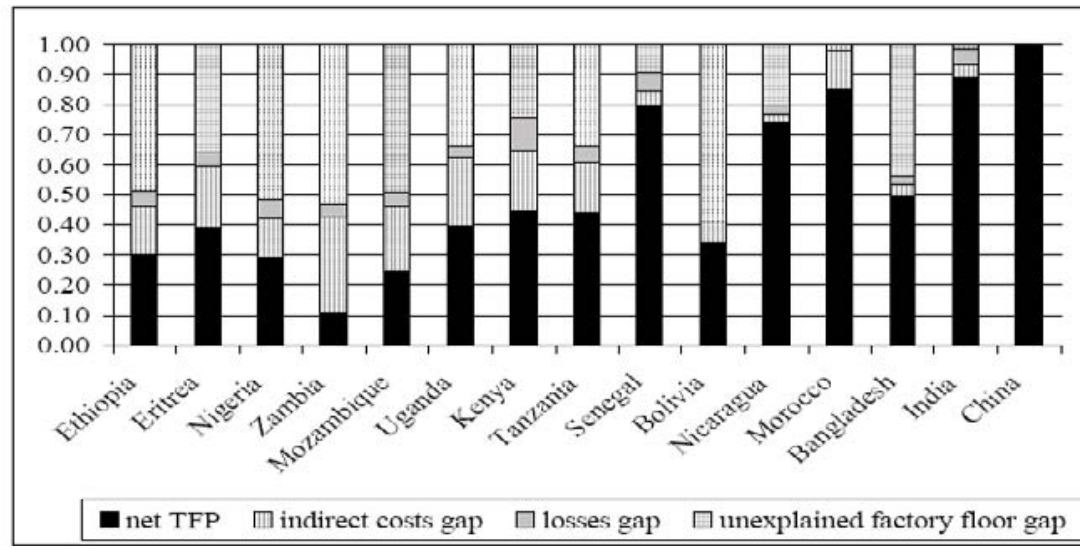

Source: Eifert, Gelb and Ramachandran (2005).

- $\quad$ Strengthening public financial management systems and wider public sector reforms will be vital to ensure that resources efficiently reach the most economically and socially productive priority sectors, including at the subnational level where some of the scaled-up resources will ultimately be spent (Box 1). Enhancing administrative capacity is also essential to effectively absorb scaled-up donor assistance. To improve the link

${ }^{21}$ See World Bank (2006) for an agricultural strategy that would build on the present approach. 
between policy objectives, appropriations and performance indicators, the government is embarking on a transition towards program-based budgeting. The government could proceed on a pilot basis with a few line ministries in 2008 budget. In support of this initiative, the CFMP will also require strengthening through a better costing of policies and more comprehensive sector strategies. In addition, the significant role played by state-owned or public-participating enterprises ${ }^{22}$ in the provision of public services, and their impact on macroeconomic developments - including domestic and external borrowing levels - argues for their consolidation into the budgetary accounts, or, at a minimum, enhanced monitoring of their activities. Finally, the international community has a role to play by including donorfinanced projects in the single treasury account and e-SISTAFE to improve timely fiscal reporting on all development expenditures and thus gauge their impact better.

${ }^{22}$ Public-participating institutions are enterprises with some private equity participation. 


\section{Box I.1. PFM Reforms in Mozambique}

PFM systems in Mozambique have shown major improvements. The public expenditure and financial accountability (PEFA) assessment of 2006 highlights that PFM systems in Mozambique have shown major improvements in recent years. The government has been implementing a nationwide PFM reform called SISTAFE, initially with substantial IMF technical assistance and more recently financed by a multidonor common fund, focusing on rolling out a government financial management information system (e-SISTAFE). e-SISTAFE has been rolled out to most line ministries at the central and provincial level by end-year 2006. The medium-term fiscal framework (CFMP) is also closely aligned with the PARPA II priorities. It was for the first time, approved by the Council of Ministers in 2006, making it a credible tool to guide the preparation of subsequent budgets. It is also possible to identify programs through Phase I of the budget formulation module of e-SISTAFE, and to track priority expenditures defined in PARPA II on a real time basis.

\section{The authorities' medium-term PFM action plan and budget (APB) covers the key areas of PFM} weaknesses identified by the 2006 PEFA assessment. According to the APB, e-SISTAFE will be extended to the remaining ministries at the central and provincial levels, and state organs by end-December 2007, and progressively rolled out to districts and municipalities (initially to 27 districts by end-October 2007). New eSISTAFE functionalities will also be implemented, particularly Phase II of budget formulation, payroll and pension, and revenue collections modules in 2007. Notably, following the completion of the census of the civil service, an integrated and e-SISTAFE compatible payroll database will be developed to carry out salary payments via direct budget execution in e-SISTAFE by end-June 2007 as it was identified by the PEFA assessment to be a major remaining fiduciary risk. ${ }^{1}$ A limited number of separate foreign currency accounts will be opened within the single treasury account in 2007 to facilitate the inclusion of donor-financed projects. As part of the decentralization efforts, a National Decentralization Strategy, including a review of intergovernmental fiscal relations, will be prepared by June 2008. Work will also continue to implement the new procurement system up to the district level. Finally, work is on-going to increase capacity of internal and external audit bodies, with specific milestones set for end-2007.

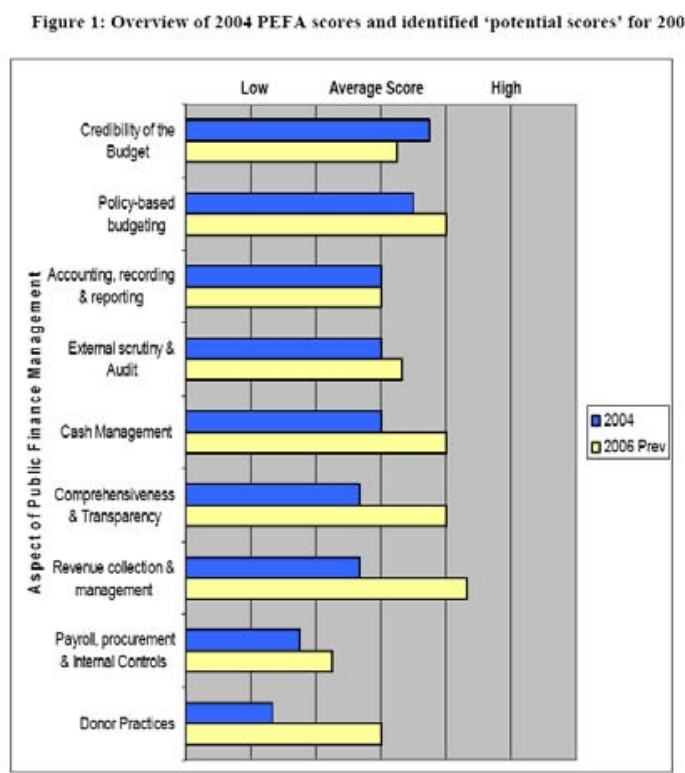

Source: PEFA (2006)

\section{Projected SISTAFE 0utputs, 2006-2009}

1. Financial and budget execution in operation in all ministries at the central, provincial and district levels, and in the municipalities and public enterprises.

2. The module of payment of salaries and pensions implemented.

3. The budget formulation module implemented (Phase II).

4. The asset management module and procurement interface implemented.

5. The ATM revenue management module implemented.

6. Program budgets under preparation by ministries.

7. The debt management module implemented.

8. The internal audit module implemented.

9. The Data Processing Centre (CPD) operating as an effective and sustainable unit.

10. Project Implementation Unit for SISTAFE operating as an effective and sustainable unit.

Source: UTRAFE, Action Plan and Budget Report, 2006-2009

1/ Payments of salaries and pension continue to be executed centrally by the accounting department of the Ministry of Finance. 


\section{An "exit" strategy and fiscal sustainability}

\section{Domestic revenue needs to gradually increase to enable an orderly exit from}

donor dependence. Following the 2015 target to achieve the MDGs, donors could revert to or decrease foreign aid from present levels. As a result, the exit strategy from aid dependence should aim to raise domestic revenue during the next eight years so that at least recurrent spending can be financed from own resources. In this way, the government can avoid recourse to unsustainable domestic borrowing (or a disruptive expenditure contraction) to offset declining external assistance. To evaluate whether the authorities long-term revenue target, as described in the accompanying Joint World Bank/IMF Debt Sustainability Analysis (DSA) is sufficient to maintain a scaling-up of aid-financed expenditures in a sustainable manner, we illustrative a fiscal framework assuming a spending of an additional US $\$ 200$ million from $2008-15$ compared to the baseline presented in the staff report. ${ }^{23}$ Given the absence of a costing of policies and sectoral interventions to achieve the MDGs, the increased expenditures is assumed to be divided between current and capital spending in a $1: 2$ ratio based on the historical distribution of aid shocks estimated in section $\mathrm{B}^{24}$ This is a simplifying assumption and would no doubt vary with the type of programs envisaged, but at least fulfills the requirement of planning for maintenance and hiring of additional personnel involved with most investments in priority sectors targeted towards achieving the MDGs.

\section{The authorities' ambitious revenue targets are adequate to gradually reduce} donor-dependence and maintain debt sustainability in the event of a moderate scalingup of expenditures. The projected revenue ratio of about 191/2 percent of GDP in 2015 (increasing from 14 percent of GDP in 2006) would cover both the scaled-up level of recurrent spending and a portion of the public investment program in the event of a US\$200 million annual scaling-up of expenditures..$^{25}$ In addition, even if one assumed that all of the scaled-up spending was financed through concessional external borrowing, the external debt-to-export ratio would still remain below the indicative performance-based debt burden thresholds (e.g., NPV of debt-to-exports ratio of 150 percent for Mozambique), which take into account the empirical finding that the debt levels that a low-income country can

\footnotetext{
${ }^{23}$ Note that the assumption of an additional US\$200 million in foreign aid is based on an indication by donors of a likely scaling-up in 2008 compared to the baseline scenario presented in the accompanying staff report.

${ }^{24}$ Note, however, that a concrete scaling-up scenario would preferably distinguish between the sectoral composition of spending, type of aid (e.g., project or program), and allocate adequate current expenditures to support the projected increases in investment including increasing demands on recurrent expenditures due to the cumulative impact of (aid-financed) public investments, which is not captured here.

${ }^{25}$ However, one must take this result with caution given the uncertainties regarding the propensity of current spending in aid-financed expenditures and present classification of most donor-financed spending as capital expenditure.
} 
sustain increase with the quality of its policies and institutions. This highlights the fiscal space available to scale-up concessional external borrowing focused on achieving the MDGs, partly as a result of MDRI aid delivery. A prudent external debt management strategy of avoiding recourse to non-concessional external borrowing has also helped and is assumed to continue. In addition, the low level of domestic public debt in Mozambique (about 8 1/2 percent of GDP), due partly to the willingness of the central bank to mop-up excess liquidity through foreign exchange sales and thus absorb foreign aid, has also contributed to a low level of debt distress It should be noted, however, that exports, revenues, and real GDP growth will play an important role in defining the scope for expanded real government spending in the context of fiscal sustainability and an acceptable level of aid dependency. ${ }^{26}$ Given this, and to safeguard the exit strategy, spending plans would need to be carefully reassessed regularly in light of the growth and Dutch-disease effects of the initial expansion in spending as well as realized revenue outcomes. As discussed in the Joint World Bank/IMF DSA any nonconcessional financing of large infrastructure projects would need to be considered case by case based on economic return, impact on debt sustainability, and potential effects on the financing decisions of donors and concessional lenders.

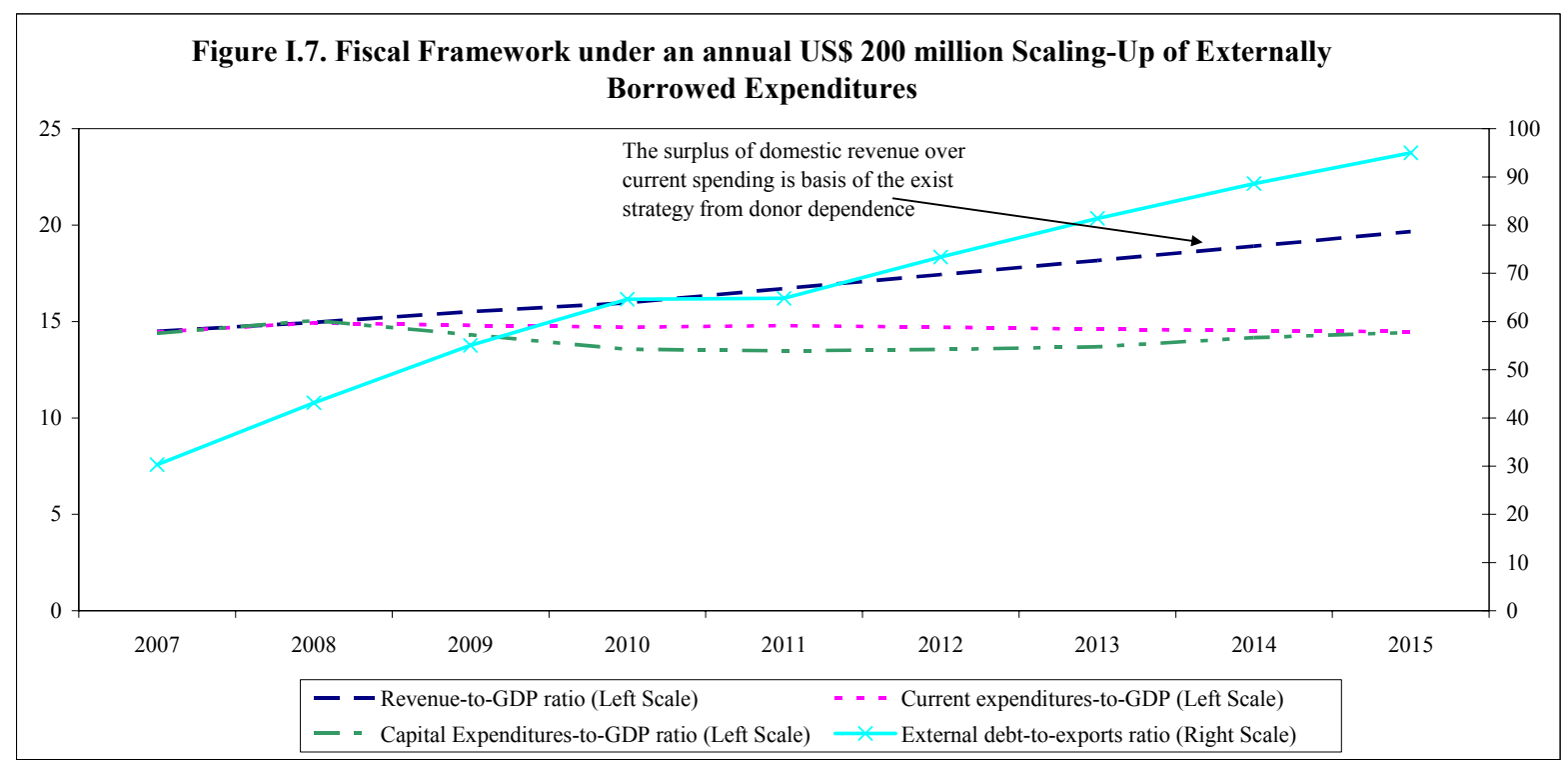

18. The ambitious revenue increase would need to be supported by continuing to implement revenue administration reforms and strengthening tax policies particularly

\footnotetext{
${ }^{26}$ Mozambique's sovereign Standard \& Poor's credit rating (B) is expected to improve, especially by buttressing institutional capacity and maintaining debt levels closer to emerging market thresholds established by Bank-Fund debt sustainability analyses. This could allow Mozambique to access international capital markets to smooth any shortfalls in donor disbursement after 2015 and/or finance large infrastructure projects to realize its full growth potential.
} 
the fiscal regime for exploitation of mineral and petroleum resources. Varsano et al., (2007) estimated the tax gap for Mozambique where actual tax collection is considered to be a function of the taxing capability, that is the maximum collection that would be possible to extract from it (which depends on the economic, social, institutional, demographic, and other characteristics of the country) and of the effort exerted in mobilizing funds for public use (determined by the tax laws and strictness with which the tax administration enforces them). The study concluded that Mozambique's tax effort (ratio between actual collection and taxing capability) was one of lowest in SSA at about 50 percent, suggesting significant scope for raising revenues, up to a level of nearly 22 percent of GDP. Schenone (2004) also estimated the difference between potential collection and actual collection due to tax laws (exemptions and nonassessments) and to noncompliance (evasion). The study found that the latter portion is much larger than the former. The implication is that although there is room for achieving an expansion of the revenues through tax policy measures, the prospects are much greater for measures that increase the efficiency of the tax administration. ${ }^{27}$ Importantly, this highlights the possibility of achieving medium-term revenue targets by widening the tax base without resorting to tax rate increases. The next phase of the revenue administration reforms (2007-10), to be supported by a multi-donor common fund, which will focus on implementing the central revenue authority (ATM) strategic plan, will be important in this regard. The ATM will be established through three stages: a transition period to end-2007, a gradual integration of the tax and customs agencies that will take place during 2008, and further strengthening and consolidation in 2009 and 2010.

\section{Mozambique's vast natural resources and present boom in commodity prices also provide a tremendous opportunity to attract greater foreign direct investment (FDI) in the mining and petroleum sectors aimed at maximizing fiscal returns and economic linkages, while minimizing environmental damage and social dislocation.} Megaprojects in the mining and petroleum sectors have put Mozambique on the global FDI map, though fiscal revenues to date have been low due to generous fiscal incentives put in place to attract private investment during the recovery from the civil war. ${ }^{28}$ Now that investor confidence in Mozambique is stronger, the authorities recognize that the fiscal contribution of new projects in these sectors could be substantially increased by reducing generous tax exemptions. As discussed in Hartley and Otto (2007), Mozambique is making important strides in this regard by putting in place a new fiscal regime for the mining sector and capacity building of personnel to negotiate effectively with multinationals through the use of financial models and model contracts. A significant amount of FDI has also flowed to the

\footnotetext{
${ }^{27}$ For example, IMF (2005c) estimated that nearly 8 percent of GDP of the total 12 percent of GDP of the revenue gap in 2003 was attributed to noncompliance, especially VAT.

${ }^{28}$ The mining sector is broadly interpreted to include Mozal, a megaproject, which produces aluminum billets from imported alumina using electricity generated by the Cahora Bassa hydroelectric plant.
} 
country's petroleum sector. ${ }^{29}$ Following agreements negotiated in 2000, the Pande-Temane gas field installations, processing facilities, and gas export pipeline to South Africa were commissioned in 2004 amounting to some US\$1 billion FDI in all. The government has also secured more than US\$300 million in petroleum exploration work commitments from the recent Rovuma Basin round, adding to perhaps US\$200 million in planned drilling and evaluation activities on contract areas awarded earlier. Mozambique has the potential to become a significant regional gas producer. Companies are exploring both for oil, and for significant gas deposits that might supply liquefied natural gas export (LNG) facilities. The Pande-Temane project (including the pipeline) is currently in a period of cost recovery and high debt service, therefore government revenues have been modest, comprising mainly petroleum production tax and a small amount of corporate income tax, but these are set to increase significantly as production ramps up and joint venture investors have recovered their initial development costs. ${ }^{30}$ Further exploration is continuing and sufficient additional reserves have been identified that the joint venture partners ${ }^{31}$ are considering a possible 50 percent expansion of the annual gas sales volume to around $180 \mathrm{mmGj}$. Even though fiscal incentives were granted for petroleum exploration, and the investors benefit from stability assurances, the current combination of economic terms for exploration and production concession contracts (EPCCs), if properly administered, should yield a share of revenues for the government that is competitive (both for government and companies) by international standards. In addition, the authorities are presenting reviewing the petroleum fiscal regime and intend to put in place a comprehensive fiscal regime that would be embodied in the general tax law to avoid case by case negotiation of petroleum tax and production sharing terms. The present mining and petroleum projects in the pipeline including the multibillion dollar Moatize coal-mine project now under negotiation could yield revenues in the range of 2-4 percent of GDP beyond 2010. Further gas and oil discoveries would result in significant revenue contributions over the long term.

\footnotetext{
${ }^{29}$ See Daniel et al., (2007).

${ }^{30}$ Under the Petroleum Production Agreement the joint venture partners are allowed 25 percent depreciation, resulting in reduced income tax revenues in the early years of the project in addition to numerous other tax exemptions.
}

${ }^{31}$ The joint venture partners are South Africa's gas giant, Sasol (70 percent), a Mozambican state-owned enterprise, $\mathrm{CMH}$ ( 25 percent) and the international finance corporation (5 percent). 


\section{Conclusions}

20. Mozambique has fully spent and mostly absorbed scaled-up foreign aid (ranging between 10-20 percent of GDP) over the last decade or so. The additional expenditures have allowed Mozambique to scale-up basic services including a doubling of the number of children in primary school, reduce infant and maternal mortality, and begin the provision of ARV treatment for HIV infections while at the same time sustaining economic growth of eight percent per year on average and reducing the poverty headcount index from 69 percent in 1997 to 54 percent in 2003. The pursuit of prudent macroeconomic policies and a first wave of structural reforms helped sustain the growth momentum by maintaining macroeconomic stability, and a sustainable fiscal and external position. Looking forward, illustrative scaling-up scenarios highlight the need to carefully manage a further scaling-up of foreign aid.

\section{A modest scaling-up of foreign aid inflows (about 2 percent of 2008 GDP) could} continue to be spent and absorbed aimed at achieving the MDGs. A scaling-up of spending, whether financed from donors or not, will tend to appreciate the real exchange rate and thus potentially hurt the export sector and long-run growth. Therefore, there is a need to effectively reach the most productive priority sectors (e.g., agriculture, education, health, infrastructure as defined in PARPA II) to illicit a supply response and mitigate potential Dutch-disease effects, by strengthening PFM systems while embarking on a public sector reform program to improve efficiency and public service delivery. Enhancing productivity growth not only requires greater productive public investments but also complementary second-generation reforms aimed at strengthening the business environment and buttressing agricultural production. It could, however, be the case that policymakers view the level of macroeconomic variables (e.g., inflation, real exchange) as well as macroeconomic volatility, even in a spend and absorb aid scenario, to be too large from a consumer welfare and/or long-term growth point of view depending on developments on the ground. This could be particularly relevant if the scaling-up is significantly larger or less persistent than the aid shock considered here or microeconomic capacity constraints start binding in some sectors. In such a case, the authorities may consider smoothing the expenditure pattern and saving part of the aid in international reserves to be spent and absorbed at a later date.

\section{Debt relief and prudent macroeconomic management has provided fiscal space} to sustain scaled-up spending, albeit with a continued need to consolidate long-term fiscal sustainability. The HIPC initiative and MDRI has reduced Mozambique's debt levels and provided fiscal space to maintain a relatively high level of expenditures (about 25-30 percent of GDP) financed through concessional external borrowing and foreign grants. The authorities strategy of absorbing foreign aid through sales of foreign exchange and avoiding recourse to nonconcessional external borrowing has also helped create a conducive environment for scaled-up expenditures. However, given the low tax-to-GDP ratio and the 
need to guard against aid volatility and gradually reduce donor dependence, an annual average revenue increase of 0.5 percent of GDP should continue to be targeted through the CFMP, achieved by widening the tax base and improving revenue administration. Beyond the PARPA II period, strong growth and increased fiscal revenues from megaprojectsincluding the development of the multibillion dollar Moatize coal-mine project and PandeTemane Gas Project — would help Mozambique maintain long-term fiscal sustainability and possibly allow it to start tapping international capital markets. This approach will provide an exit strategy from aid dependence in the long-run and ensure that at least recurrent spending can be financed from own resources. 


\section{References}

Arndt, C., Jones, S., and F. Tarp, 2007, "Aid and Development: the Mozambican Case," in Lahiri, S., editor, Theory and Practice of Foreign Aid, Vol. 1 of Frontiers of Economics and Globalization (Amsterdam: Elsevier, North Holland).

Benito-Spinetto, M., and P. Moll, 2005, "Mozambique: Background Paper: Macroeconomic Developments, Economic Growth and Consequences for Poverty," Background paper, The World Bank Africa Region Working Paper Series (Washington: World Bank).

Bourguignon, F. and M. Sundberg, 2006, "Absorptive Capacity and Achieving the MDGs," Research Paper 2006/47 (Helsinki: UNU-WIDER).

Buffie, Edward, Christopher Adam, Stephen O'Connell, and Catherine Pattillo, 2007, "Monetary Policy Rules for Managing Aid Surges in Africa," forthcoming IMF Working Paper (Washington: International Monetary Fund).

Chistiano, L, M. Eichenbaum, and C. Evans, 2005, "Nominal Rigidities and the Dynamic Effects of a Shock to Monetary Policy," Journal of Political Economy, Vol.113. Commission for Africa, 2005, "Our Common Interest: Report of the Commission for Africa" (London).

Daniel, P. Dourado, D. A. Puyo, and Alistair Watson, 2007, "The Petroleum Sector: Fiscal and Economic Terms," Aide-Mémoire of the Fiscal Affairs Department mission, (Washington: International Monetary Fund).

Devarajan, Shantayanan, Delfin S. Go, Jeffrey D. Lewis, Sherman Robinson, Pekka Sinko, 1994. "Policy Lessons from a Simple Open-economy Model," Policy Research Working Paper 1375 (Washington: World Bank).

Eifert, Benn, Alan Gelb, and Vijaya Ramachandran, 2005, "Business Environment and Comparative Advantage in Africa: Evidence from the Investment Climate Data," Working Paper No. 56 (Washington: Center for Global Development).

Fox, Luise, Rui Benfica and Melissa Sekkel, 2007, "Halving the Poverty Rate by 2015," unpublished manuscript.

Gupta, Sanjeev, Benedict Clements, Emanuele Baldacci, and Carlos Mulas-Granados, 2004, in Sanjeev Gupta, Benedict Clements, and Gabriela Inchauste, eds., Helping Countries Develop: The Role of Fiscal Policy (Washington: International Monetary Fund)

Hartley, J. and J. Otto, 2007, "Mineral Resources Management: from Curse to a Virtuous Cycle," unpublished manuscript.

Hendry, D. F., 1995, Dynamic Econometrics, (Cambridge, U.K.:Oxford University Press). International Monetary Fund, 2005a, The Macroeconomics of Managing Increased Aid Inflows: Experiences of Low-Income Countries and Policy Implications, (Washington: International Monetary Fund, Policy Development and Review Department). 
International Monetary Fund, 2005b, Update on the Assessments and Implementation of Action Plans to Strengthen Capacity of HIPCs to Track Poverty-Reducing Public Spending, (Washington: International Monetary Fund, Fiscal Affairs Department and the World Bank's Poverty-Reduction and Economic Management Network). International Monetary Fund, 2005c, "Mozambique: Selected Issues and Statistical Appendix," IMF Country Report 05/311 (Washington: International Monetary Fund) International Monetary Fund, 2006, The Macroeconomic Challenges of Scaling-Up Aid to Africa (Washington: International Monetary Fund, African Department). Jones, S., 2007, "Sustaining Growth in the Long Term," unpublished manuscript. Johnson, Simon, Jonathan D. Ostry, and Arvind Subramanian, 2007, "The Prospects for Sustained Growth in Africa: Benchmarking the Constraints," IMF Working Paper 07/52 (Washington: International Monetary Fund).

Mattina, Todd D, 2006, "Money isn't Everything: The Challenge of Scaling Up Aid to Achieve the Millennium Development Goals in Ethiopia," IMF Working Paper 06/192 (Washington: International Monetary Fund).

Mavrotas, G. 2002, “Foreign Aid and Fiscal Response: Does Disaggregation Matter?," Review of World Economics Vol. 138, No.3.

McGillivray, Mark, Sonja Fagernäs, and John Roberts, 2004, "Fiscal Impact of Aid: A Survey of Issues and Synthesis of Country Studies of Malawi, Uganda and Zambia," Economic and Statistics Analysis Unit (United Kingdom: Overseas Development Institute).

McGillivray, M., and O. Morrissey, 2001, "Fiscal Effects of Aid," WIDER Research Paper DP 2001/61 (Helsinki: UNU-WIDER).

Osei, R, O. Morrissey, and T. Lloyd, "Fiscal Effects of Aid in Ghana, 2005," WIDER Discussion Paper 2005/61 (Helsinki: UNU-WIDER).

Peiris, S. J. and M. Saxegaard, 2007, "Monetary Policy in Sub-Saharan Africa: Lessons from a Dynamic Stochastic General Equilibrium Model Applied to Mozambique," unpublished manuscript.

Prati, A. and T. Tressel, 2006, "Aid Volatility and Dutch Disease: Is there a Role for Macroeconomic Policies?," unpublished manuscript.

Schenone, O., 2004, "Mozambique: A Methodology for Tax Revenue Estimation,” Technical Assistance Report from the Fiscal Affairs Department (Washington: International Monetary Fund).

Varsano, R. Odette de Oliveira, R. M. Villela, and Irene Yackovlev, 2007, "Mozambique: Evaluation of the Post-Reforms Tax System," Technical Assistance Report from the Fiscal Affairs Department (Washington: International Monetary Fund).

World Bank, 2005, "Mozambique Country Economic Memorandum: Sustaining Growth and Reducing Poverty," Report 32615-MZ (Washington: World Bank).

World Bank, 2006, "Mozambique Agricultural Development Strategy: Stimulating Smallholder Agricultural Growth," Report No. 32416-MZ (Washington: World Bank). 


\section{Evaluating Mozambique's Financial Sector Reform Strategy ${ }^{32}$}

\section{A. Introduction}

\section{Financial sector development is an important objective of Mozambique's}

poverty reduction strategy. Empirical evidence has consistently confirmed financial sector development as an essential enabler of sustainable economic growth periods. ${ }^{33}$

Mozambique's new PRSP (PARPA II in Portuguese) has taken that into consideration by selecting financial sector development as one of the main objectives of its economic development pillar. $^{34}$

\section{Mozambique's financial sector strategy provides some important lessons on} how to manage financial sector reforms in low-income countries. While institutional obstacles continue to constrain financial intermediation, Mozambique has made substantial progress in promoting financial liberalization, and restructuring its banking sector over the past ten years. Mozambique is now deepening those reforms by strengthening the institutional regulatory architecture for financial sector development within the framework of a financial sector development strategy developed after the 2003 financial sector assessment of its financial sector. This chapter will take a closer look at the ongoing reforms with a view to assess the extent to which they address the most critical financing constraints, and are implemented with the appropriate ownership and coordination, so as to ensure the sustainability of the reform process. Section B summarizes the main weaknesses of the financial sector in 2002 and reform priorities resulting from the 2003 Financial Sector Assessment Program (FSAP). Section C outlines Mozambique's current financial sector strategy. Section D takes stock of the reform progress to date. Section E concludes with some policy lessons and implementation challenges that lie ahead.

\section{B. Diagnosing Mozambique's Financial Sector}

\section{Though still small, and fairly underdeveloped in 2002, Mozambique's financial} system had come a long way since the end of the civil war-evolving from a

\footnotetext{
${ }^{32}$ Prepared by Victor Lledó. This chapter has benefited from valuable comments from the Bank of Mozambique and the World Bank.

${ }^{33}$ See Levine (2005) for a survey of the empirical literature and IMF (2006) for an analysis of the Asian experience.

${ }^{34}$ PARPA II has three pillars (i) governance, (ii) human capital, and (iii) economic development. The economic development pillar, in turn, focuses on promoting private sector development, including through measures to increase the soundness and depth of the financial system.
} 
government-owned system to a full-blown, market-based financial system. ${ }^{35}$ Then, the financial system was dominated by foreign banks and highly concentrated with the five largest banks accounting for 96 percent of total deposits at end 2002 (Table 1). ${ }^{36}$ The system had also become increasingly dollarized: foreign currency deposits, and loans accounting for 51 percent and 70 percent of their respective totals in 2002. The system's role in financial intermediation was also underdeveloped even by regional standards, as reflected in its small credit to GDP ratio, and loan to deposit ratio. While Mozambican banks were deemed generally profitable, and well capitalized, they were exposed to significant credit risk as reflected in the high ratio of nonperforming loans (NPL) to total loans (21 percent at end2002).

Table II.1. Mozambique and Comparators: Financial Intermediation , 2002

\begin{tabular}{|c|c|c|c|c|}
\hline & Private Credit & Deposits & Deposit Dollarization & Bank Concentration \\
\hline & \multicolumn{2}{|c|}{ Percent of GDP } & Percent of total deposits & Percent of largest five banks \\
\hline Mozambique & 14 & 23 & 57 & 96 \\
\hline Sub-Saharan Africa & 26 & 27 & 42 & 83 \\
\hline Low-Income & 18 & 21 & 49 & 71 \\
\hline
\end{tabular}

Sources: IFS, and Barth, Caprio and Levine (2004).

\section{Mozambique's high lending rates and poor financial intermediation were} considered to be partly the result of high credit risk with deeper structural implications. Real lending rates in Meticais in the period 1999-2002 averaged 17.5 percent. Such high rates mostly reflected very large intermediation spreads, which according to a decomposition exercise conducted in the FSAP (Figure 1), were partly caused by high levels of NPLs made to state-owned enterprises and other non-compliant borrowers in the aftermath of the bank privatization process in the mid-nineties. This problem reflected the lack of a mandate and capacity to effectively supervise banks and was compounded by the lack of adequate reporting standards for effectively

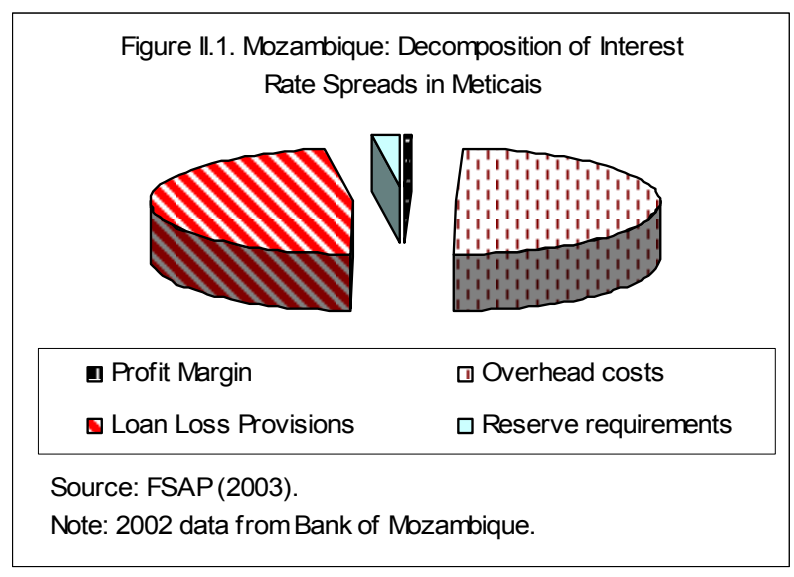
monitoring the soundness of bank lending. Other factors included (i) high overhead costs,

\footnotetext{
352002 was the latest year for which data were available at the time of the FSAP diagnostics.

${ }^{36}$ This high level of concentration was mostly due to the merger of the parents of the two largest banks in their home market of Portugal.
} 
partly reflecting the small size of the Mozambican financial system, (ii) high reserve requirements, and (iii) generally substantial profit margins, reflecting high bank concentration and limited competition.

\section{Financial intermediation was also constrained by legal and institutional}

impediments. Mozambican's high credit risk and poor financial intermediation were partly attributed to the lack of institutional capacity to (i) enable lenders to collect debt upon default including efficient debt enforcement for unsecured loans through the courts, comprehensive laws for taking and enforcing security through collateral systems, and efficient bankruptcy laws, and (ii) assist lenders in their credit selection decisions by disseminating information on borrower's creditworthiness (Box 1). In the absence of institutions that facilitate loan recovery and contract enforcement, banks were led to adopt a conservative stance toward smaller borrowers in their lending policies by restricting access and pushing up lending rates. Lack of information on borrowers' creditworthiness further aggravated this problem; indeed, it increased uncertainty regarding nonperforming loans forcing banks to increase loan loss provisions (with direct implications to the cost of credit), impose stringent collateral requirements, or simply refuse credit to applicants with no previous credit history. Business surveys at the time also corroborated this view by showing that, given the high cost of finance, and high level of collateral required, Mozambican enterprises were severely capitalconstrained with an overwhelming majority using retained earnings to finance capital accumulation (World Bank 2003).

\section{High and volatile real treasury bill rates were also partly affected by weaknesses} in monetary and public debt management stemming from the unstable macroeconomic environment. ${ }^{37}$ Mozambique has long been subject to significant supply shocks (e.g., related to weather and terms of trade) and to large fiscally-induced, demand shocks (i.e., unanticipated influx of external grants and loans). Weaknesses in the monetary framework and liquidity management operations have prevented monetary authorities from cushioning those shocks in a systematic, credible, and transparent way, causing, at times, substantial volatility in both prices and nominal interest rates (Box 2). Real interest volatility was further exacerbated by the shallow foreign exchange and public debt markets.

\footnotetext{
${ }^{37}$ Boyd, Levine, and Smith (2001) have shown that low levels of financial intermediation are partially explained by high volatility in interest rates and monetary aggregates, a result that was robust to reverse causation and simultaneity bias.
} 


\section{Box II.1. Institutional Roots of Poor Financial Intermediation in Mozambique}

Mozambique's lending environment was hampered by poor enforcement and securitization of lending contracts. As a result of inefficient courts, Mozambique ranked very poorly both regionally and internationally on contract enforcement, as measured by the high number of procedures, the long delays, and the high cost to enforce commercial contracts. Pledging real property as a collateral was also very difficult because of weak property rights; and complex and costly procedures to register and transfer property.

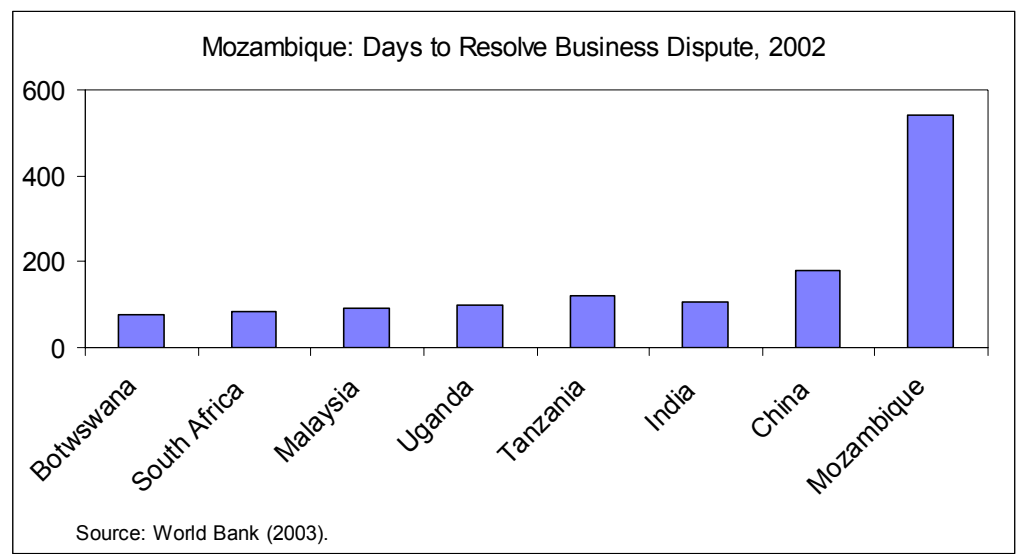

The coverage and scope of credit registries in Mozambique was limited. Mozambique had no private credit bureau and its public credit registry run by the central bank, while generally a well-functioning institution had a narrow scope and lacked reliability. The public credit registry covered only about 11,500 borrowers (firms and individuals), did not include credit information compiled by nonfinancial institutions such as utility payments and retail credit, and has limited resources (only three full-time staff). Though the situation has since improved - borrowers increased to about 99,000 in 2006 - its overall quality still falls short of regional best practices, and a number of ASEAN 4 countries.

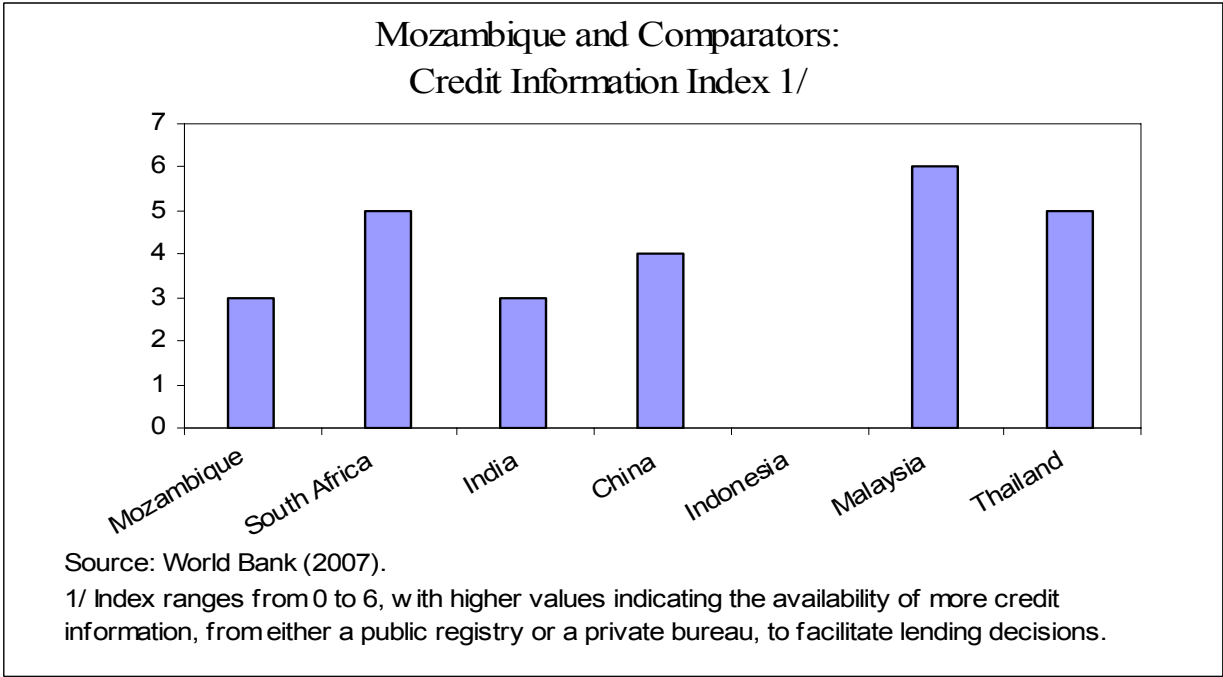




\section{Box II.2. Weaknesses in Monetary Policy Management}

Effective monetary policy and public debt management in Mozambique are compromised by weaknesses in the (i) monetary framework, and (ii) Bank of Mozambique's (BM) net financial position.

The monetary framework lacked transparency. Market participants did not fully understand the goals or operational framework of the monetary policy. This partly reflected insufficient efforts of the BM in communicating with market participants, as well as inconsistencies in the use of instruments that send conflicting signals on the BM monetary policy stance.

BM's fragile financial position risked its operational independence. While BM reported positive capital and declared operating profits in recent years, its net worth and profits become negative once valuation adjustments are properly accounted for. BM losses originated mainly from (i) accumulated foreign exchange valuation losses on BM external liabilities to foreign lenders, and (ii) operating losses stemming from the purpose of sterilization (costs of monetary policy) not transferred to the budget.

29. According to the 2003 FSAP, access to affordable finance was hampered by the poor outreach among financial institutions and its impact on savings mobilization.

Financial savings mobilization was deemed constrained not only by Mozambique's lowincome levels but also by a thin branch network of banks, particularly in rural areas (Table 2). The situation was further aggravated by the relatively small size, and outreach of the microfinance industry. Constraints to providing financial services in rural and remote areas were widely noted to include very low population densities, weak or nonexistent markets, poor physical and communication infrastructure, and the local unavailability of skilled staff.

Table II. 2. Mozambique and Comparators: Savings Mobilization, Branch Density, 2002

\begin{tabular}{lcccc}
\hline & $\begin{array}{c}\text { GDP per Capita } \\
\text { (constant 2000 US\$) }\end{array}$ & $\begin{array}{c}\text { Population Density } \\
\text { (population per sq km) }\end{array}$ & $\begin{array}{c}\text { Population } \\
\text { per branch }\end{array}$ & $\begin{array}{c}\text { Gross Domestic Savings } \\
\text { (percent of GDP) }\end{array}$ \\
\hline Mozambique & & & & 85,645 \\
South Africa & 200 & 23.0 & 16,842 & 11.0 \\
Tanzania & 3,093 & 34.5 & 173,998 & 20.2 \\
Zambia & 271 & 39.0 & 66,339 & 11.6 \\
India & 354 & 13.8 & 14,888 & 17.7 \\
Indonesia & 448 & 338.4 & 12,547 & 24.3 \\
\hline
\end{tabular}

Sources:World Bank, World Development Indicators.

\section{Nonbank financial institutions (NBFI) were small, nontransparent and subject} to limited institutional and regulatory oversight. As such, they could mask sizeable contingent fiscal liabilities. The situation was particularly critical in the insurance and pension sectors, where supervisory capacity was weak and diluted between the Ministry of Finance (insurance) and the state pension scheme, INSS (pensions), which, in turn, had both an administrative and a prudential mandate. 
31. Tackling the identified weaknesses in the financial sector required measures to (i) strengthen banking supervision and reporting standards, (ii) refine the management of monetary policy and public debt, and (iii) improve the institutional lending environment (Box 3). Measures to support the soundness of banks included addressing potential shortfalls in banking supervision and reporting standards. To limit the volatility in prices and interest rates, refinements in monetary policy formulation would need to be prioritized. Further, the reform efforts were to be directed toward improving the legal and institutional environment for lending followed by a more gradual process of reforms to promote the sound development of nonbank financial institutions initially by enhancing its regulatory and supervisory framework. Underlying FSAP recommendations, there was a clear sense that financial sector development should have been initially pursued through measures to ensure financial sector stability given the recent (and at the time not yet resolved) banking restructuring episode, and continued volatility in prices and interest rates.

\section{Mozambique's Financial Sector Reform Strategy}

\section{To address the above challenges, the government developed in collaboration} with donors a comprehensive financial sector reform strategy. Financing for the capacity building and implementation of the strategy was provided as a multiple donor program under one umbrella referred as the Financial Sector Technical Assistance Project (FSTAP). Mozambique's FSTAP is a comprehensive financial sector reform program focused on (i) strengthening the banking sector and enhancing the capacity of the BM in terms of banking supervision, managing the banking system, and financial infrastructure, including real time gross settlement system; (ii) improving financial accountability and transparency by the introduction of international financial reporting standards (IFRS) to commercial banks (first phase) and corporate entities (second phase); (iii) strengthening public debt management capacity, including the development of a debt management strategy and reorganization and strengthening of the public debt department of the Ministry of Finance; and (iv) improving money and government bond market efficiency and depth, including the introduction of a central securities depository. The IMF plays an important role in the FSTAP by providing technical assistance in a number of areas in close coordination with the government and other donors. The remainder of this section outlines the elements of this strategy by describing the main features of the FSTAP, including the prioritization and sequencing; financing, implementation and coordination arrangements, and monitoring. 


\section{Box II.3. Summary of Key FSAP Recommendations}

\section{Banking Supervision and Reporting Standards}

- Establish closer links with foreign shareholders and their supervisors;

- Bring the loan classification system and loan loss provisioning system in line with international practices;

- Strengthen and modernize supervisory functions through capacity building and reorganization;

- Define a program towards full adoption of IFRS; and

- Review the legal and regulatory framework for bank resolution.

\section{Monetary Policy and Public Debt Management}

- Make monetary policy more effective by:

i. Ensuring consistency between the use of instruments and the policy framework to support the monetary targeting framework;

ii. Introducing new instruments (repos/reverse repos) for short-term liquidity management and direct foreign exchange interventions to smooth volatility in the foreign exchange market;

iii. Enhancing the central bank's capacity to provide accurate and timely forecasts of short-term liquidity flows in coordination with Ministry of Finance; and

iv. Improving the central bank's communication strategy by establishing a monetary policy strategy document and selecting ways to better disseminate monetary policy decisions.

- Ensure BM's operational independence by:

i. Transfering medium- and long-term foreign (HIPC) debts to treasury; and

ii. Reviewing accounting and profit transfer practices to shift monetary policy costs to the Ministry of Finance.

- Strengthen public debt management operations by:

i. Improving information analysis and reporting and formulating a debt management strategy; and

ii. Restructuring the Public Debt Unit of the Ministry of Finance;

\section{Institutional Lending Environment}

i. Enact proposed amendments to BM law and the Banking Law;

ii. Review Commercial Code;

iii. Modernize the Notary Office, the Public Commercial Registry, and Code of Civil Procedure;

iv. Establish a special division of the Maputo City Court to execute judgments;

v. Update the legal framework for secured transactions; and

vi. Consider establishing a specialized commercial court.

\section{Capital Market, Pensions, Insurance}

i. Review regulation on capital controls and build up supervisory capacity;

ii. Improve accounting and disclosure standards for insurance and pensions; and

iii. Separate supervisory and administrative functions of state pension scheme (INSS).

\section{Microfinance}

i. Review draft legislation on microfinance. 


\section{Reform priorities}

\section{The government's reform priorities were in line with the 2003 FSAP}

recommendations. Given the dominant role of banks in Mozambique's financial system and in particular its fragile state at the time the reform was conceived the government reform strategy prioritized measures to (i) support bank soundness by promoting transparency and disclosure, and by strengthening of BM's supervisory capacity; and (ii) deepen financial markets denominated in local currency through a concerted effort to strengthen monetary, foreign exchange, and public debt management. The strategy also included measures to reform the institutional lending environment with a view to improving access to credit. Given its small size, more fundamental reforms to support the development of markets for longer term financial obligations (e.g., pensions, insurance, and housing) were left to a later stage with immediate priority given to strengthen supervisory capacity in line with those envisaged for the banking sector so as to avoid regulatory arbitrage.

\section{Reform areas and donor involvement}

\section{The reform strategy has been operationalized into one project with ten} components supported by multiple donors (Box 4, Table 3). The reform priorities to improve banking soundness and deepen money and debt markets have four components and are being financed by the World Bank (IDA) with the IMF, the United Kingdom's Department of International Development (DFID), and Sweden International Development Association (SIDA) providing complementary technical assistance. The African Development Bank (AfDB) supports four components in the areas of institutional lending environment, development of pension and insurance markets, and anti-money laundering. The German Technical Cooperation (GTZ), and the German Fund for Reconstruction (KfW) jointly managed and finances a component looking at measures to improve access to financial services by supporting microfinance and rural finance institutions. ${ }^{38}$ Besides the nine technical components referred above, a tenth administrative component financed and managed by the World Bank established a project implementation unit responsible for all fiduciary activities (accounting, reporting, and auditing).

\footnotetext{
38 Access to financial services in rural areas is also being addressed by a joint AfDB/ International Fund for Agriculture Development (IFAD) under the Rural Finance Support Program (RFSP). This projects aims to support policy, legal, regulatory, and institutional aspects of rural finance.
} 
Table II. 3. Mozambique : FSTAP Support by Components and Agencies

\begin{tabular}{|c|c|c|c|c|c|c|}
\hline & \multicolumn{6}{|c|}{ Agencies } \\
\hline & IDA & AfDB & DFID & SIDA & KfW/GTZ & IMF \\
\hline & \multicolumn{6}{|c|}{$(\mathrm{F}=$ financier, $\mathrm{T}=$ technical assistance provider $)$} \\
\hline Component & & & & & & \\
\hline 1. Banking Sector & $\mathrm{F}, \mathrm{T}$ & & $\mathrm{T}$ & & & $\mathrm{T}$ \\
\hline 2. Financial Accountability/Transparency & $\mathrm{F}$ & & $\mathrm{F}, \mathrm{T}$ & & & \\
\hline 3. Public Debt Management & $\mathrm{F}, \mathrm{T}$ & & & $\mathrm{F}$ & & \\
\hline 4. Money and Debt Markets & $\mathrm{F}, \mathrm{T}$ & & & & & $\mathrm{T}$ \\
\hline 5. Micro and Rural Finance & & $\mathrm{F}^{1 /}$ & & & $\mathrm{F}, \mathrm{T}$ & \\
\hline 6. Insurance & & $\mathrm{F}$ & & & & \\
\hline 7. Social Security System & & $\mathrm{F}$ & & & & \\
\hline 8. Lending Environment & & $\mathrm{F}$ & & & & \\
\hline 9. Anti-money laundering & & $\mathrm{F}$ & & & & $\mathrm{T}$ \\
\hline 10. Project management & $\mathrm{F}$ & $F$ & $\mathrm{~F}$ & $F$ & $\mathrm{~F}$ & \\
\hline
\end{tabular}

Source : World Bank (2005).

Note : 1/Provided in collaboration with the International Fund for Agriculture Development outside FSTAP under the Rural Finance Support Program.

\section{Implementation and coordination arrangements}

\section{Mozambique's financial sector reform strategy incorporates novel}

implementation arrangements. As discussed above, while funding for each project is provided separately by multiple donors, ultimate responsibility for implementation lies in the project implementation unit (PIU). The PIU is headed by a project coordinator who reports to the Ministry of Finance and is responsible for providing guidance on procurement of goods and services, monitoring and evaluation, and the overall thrust of financial sector reforms. In line with the guidelines for harmonization and alignment established under the Paris Declaration for Aid Effectiveness, this arrangement seeks to reduce transaction costs and promote donor coordination by avoiding the duplication of parallel implementation units, while fostering country ownership and coordination as the ultimate responsibility for implementation lies in one government agency.

\section{Monitoring and evaluation}

\section{The reform strategy is monitored by measurable performance indicators and} systematically evaluated by government and development partners. An action plan (i.e., a results framework matrix specifying objectives and corresponding performance indicators) for each of the FSTAP components spans the program's five years. ${ }^{39}$ On the basis of these results frameworks, quarterly monitoring tables, and progress reports are prepared by the PIU and discussed by a technical working group (TWG) jointly chaired by the PIU coordinator, its procurement officer and representatives of the beneficiaries government agencies involved. Actions identified as high priority by the government and donors within the results framework are also included in the Performance Assessment Framework (PAF) Matrix, which is the common monitoring mechanism used by the government and donors to evaluate

\footnotetext{
${ }^{39}$ The results framework matrix is summarized in the appendix.
} 
progress on the overall poverty reduction strategy on an annual basis. A medium-term review of the strategy is expected to take place at the end-2008, which will include an assessment of the effectiveness of the reform program and will be preceded by a reappraisal of the identified obstacles to the soundness and depth of Mozambique's financial system (the latter in the context of an FSAP update).

\section{Box II. 4. Key Elements of the Reform Strategy: FSTAP Components}

Technical and financial support for Mozambique's financial sector reform strategy is provided through the FSTAP under its nine components; a list of some of their corresponding key measures is described below.

\section{Component 1: Strengthening BM's Institutional Capacity}

(i) Support BM's Banking Supervision Department (BSD) towards full implementation of Basel I principles including preparation of new inspections manuals, drafting of prudential regulations (focus on loan classification and consolidated supervision), and on-the-job training;

(ii) Consultancy services to assist BM draft a bankruptcy law applicable to financial institutions;

(iii) Prepare a supervisory framework and training for NBFIs on new risks (anti-money laundering; new instruments (electronic banking, leasing, and factoring);

(iv) Improve information technology and transition of central bank accounting into IFRS including revision of the Chart of Accounts;

(v) Strengthen analytical capacity at BM's research department; and

(vi) Divest the government of its remaining shareholdings of financial institutions.

\section{Component 2: Improving Financial Accountability and Transparency}

(i) Adopt and implement IFRS applicable to commercial banks;

(ii) Transition of corporate sector to IFRS;

(iii) Establish a central securities depository for government debt instruments; and

(iv) Implement effective procedures for the registration of private debt in the BM.

\section{Component 3: Strengthening Public Debt Management}

(i) Formulate a public debt management strategy;

(ii) Improve liquidity management policies and procedures;

(iii) Restructure the public debt unit of the Ministry of Finance and strengthen procedures and controls, and staff capacity building including information analysis and reporting; and

(iv) Consolidate and reconcile the debt database for all public debt.

\section{Component 4: Improving Money and Debt Markets and Financial Infrastructure}

(i) Improve primary and secondary government debt market; and

(ii) Improve the monetary policy framework and develop the repurchase (repo) market.

\section{Component 5: Micro and Rural Finance}

(i) Support strengthening of micro and rural finance institutions; and

(ii) Promote rural expansion and the integration of microfinance institutions (MFIs) in the financial system.

Cont... 


\section{Box II.4. (cont). FSTAP Components}

\section{Component 6: Strengthening the Insurance and Supplementary Pension System}

(i) Fine-tune insurance law to (a) adopt international best practices in the regulation of insurance contracts, (b) provide guidelines on investments by insurance companies to ensure risk diversification; and (c) empower Mozambique's insurance regulator (IGS);

(ii) Establish a supervisory framework and prudential regulations to guide the conduct of the insurance sector;

(iii) Develop pension funds legislation; and

(iv) Improve capacity at IGS.

Component 7: Strengthening the Social Security System

(i) Conduct a study on affordable options for improving social security coverage;

(ii) Address INSS organizational, transparency, and accountability deficiencies; and

(iii) Perform an actuarial analysis of the compulsory social protection system.

Component 8: Improving the legal and judicial environment for financial transactions

(i) Develop a new Bankruptcy Law;

(ii) Establish commercial sections in the Judicial Tribunals of the City of Maputo and the Provinces of Beira and Nampula;

(iii) Modernize and link the property registries electronically; and

(iv) Enhance the scope and reliability of the credit registry.

Component 9: Support for Anti-Money Laundering Efforts

(i) Establish the Financial Intelligence Unit.

\section{Component 10: Support for Project Implementation}

(i) Finance implementation costs with consultancies, financial advisor, personnel, training, and office equipment.

Source: World Bank (2005).

\section{Capacity building}

\section{Capacity building is a central element in Mozambique's financial sector reform}

strategy. The success and sustainability of reform programs depends to a large extent on local capacity to analyze issues and to redesign and implement strategies in the face of changing circumstances. The FSTAP accordingly includes capacity building measures in most of its components. The IMF plays an important role in this regard providing technical assistance in close coordination with other FSTAP agents to improve BM's liquidity management, monetary and exchange rate policy operations, and financial sector supervisory capacities. In consultation with government authorities and donors, a technical assistance strategy specifying priority areas and modes of delivery has been prepared (Box 5). 


\section{Box II.5. IMF Technical Assistance Strategy}

IMF technical assistance priorities are: (i) making monetary policy more effective; (ii) further strengthening the supervisory and regulatory framework to foster the sound expansion of the financial sector and achieve full compliance with international standards in accounting, anti-money laundering, and banking supervision; and (iii) developing interbank foreign exchange market and government debt management capacity to support financial deepening and smooth monetary policy transmission. These priorities are supported by

- $\quad$ Annual multi-topic TA missions to follow up on financial sector reforms with targeted peripatetic expert visits in priority areas including bank supervision, liquidity forecasting and monetary operations.

- $\quad$ An FSAP update in 2008 to take stock of reforms to date and map out future reform priorities with regard to access, cost of finance, and financial stability.

\section{Taking Stock of the Reform Progress}

\section{Reform effort to date}

38. Efforts since the 2003 FSAP have focused on restructuring and strengthening the supervision of Mozambique's banking system. Mozambique's bank privatization process has been plagued by lack of due diligence resulting in costly recapitalizations from the government during $2000-02 .{ }^{40}$ However, over the last four years, the government has demonstrated its commitment to return banks to private ownership and remains a minority shareholder of only one bank for which intentions to withdraw have already been publicly announced. Reform efforts have also been more pronounced in the area of banking supervision and reporting standards (Box 6). To dispel uncertainties about the overall condition of the banking system following the restructuring, the government allowed the comprehensive diagnostic reviews of the major banks in Mozambique by international firms according to IFRS. These reviews, which were concluded in 2005, endorsed the overall soundness of the banking system. A new law strengthening the BM's supervisory and enforcement mandates has also been implemented with capacity building being provided by the IMF, World Bank, and other donors.

\footnotetext{
${ }^{40}$ The privatization process started in the mid-1990s. Subsequent crises at both Banco Austral and Banco Comercial de Moçambique required recapitalizations, amounting to 6 percent of GDP.
} 


\section{Box II.6. Strengthening Banking Supervision and Regulatory Environment in Mozambique}

Measures adopted after the FSAP included :

1. Comprehensive diagnostic reviews of the major banks by international firms according to IFRS (completed in 2005).

2. The implementation in 2004 of a new Financial Institutions Law strengthening the central bank's supervisory powers and introducing more strict penalties for noncompliance violations.

3. Continued progress to strengthen banking supervision practices in line with Basel Core Principles (BCP) by (i) building on- and off-site supervisory capacity; (ii) requiring the preparation of financial statements of Mozambique's financial institutions and corporate sector in compliance with international, and (iii) adopting prudential regulations in line with international best practices.

4. Adoption of IFRS by the BM in 2006 and by commercial banks in 2007 .

\section{While there has been some recent progress in improving the monetary} framework, important measures to enhance monetary policy operations and public debt management have yet to be implemented. The BM has taken important steps to strengthen its monetary policy operations by increasing the use of foreign exchange sales to sterilize excessive liquidity and allowing the issuance of treasury-bills for monetary policy purposes. Monetary authorities are currently working to implement several measures to improve its liquidity management practices and forecast, to ensure its operational independency, and to deepen its foreign exchange, money, and debt markets (Box 7).

\section{Reform in the institutional lending environment has been more recent. Among} the few achievements on the legal front have been the implementation of the new Commercial Code, and the establishment of the commercial sections of the judicial tribunals in the cities of Maputo, Beira, and Nampula. The former will help relieve the overburdened judicial system by avoiding commercial disputes. The latter, which will become operational in 2007, is expected to accelerate debt recovery of unsecured lending once appropriate equipment; facilities and capacity building are provided. Debt recovery is expected to be accelerated even further once a revised Civil Procedure Code with streamlined judicial procedures is enacted. However, despite these encouraging steps, significant measures to improve the lending environment are still required (Box 8).

\section{The government has taken initial steps to support a sound expansion of NBFIs.}

The BM has started to license and supervise deposit-taking MFIs. A new law on social protection recently submitted to the Assembly will help strengthen the social security and supplementary pension system. As part of the restructuring of the INSS, an actuarial study to determine whether the current level of contributions is capable of sustaining the scheme of benefits covered will be completed before the end of 2007. The government is also 
enhancing the regulatory and supervisory framework for the pension and insurance sector. The Insurance Law is being reviewed in line with international best practices, and revised prudential and solvency requirements for Mozambican insurers are being developed, while new IFRS-compliant Chart of Accounts for insurers will also be designed. New supplementary pension funds regulations are also being prepared. Looking ahead, the focus would need to shift to strengthening the capacity of industry regulators.

\section{Increasing attention is being devoted to rural financing issues. As part of the} overall reform effort to increase access to financial services in rural areas, the government has recently launched a package of initiatives to enhance the physical presence of banks in rural districts. Proposed measures are mostly targeted to reduce the operational costs of providing banking services in rural areas through the provision of fiscal incentives, infrastructure improvements, and by relaxing legal reserve requirements in rural branches so as to include cash in vault. ${ }^{41}$ Transport costs related to the constitution of legal reserves, and cash in vault for immediate withdrawal have been further minimized with the opening of BM branches in selected districts.

${ }^{41}$ Fiscal incentives in the form of grant and loan resources are partially provided under the Rural Finance Support Program (RFSP) financed by the AfDB and IFAD. 


\section{Box II.7. Strengthening Monetary and Public Debt Management in Mozambique}

Monetary policy framework. The BM has adopted a money targeting framework using base money as the operational target. In order to improve BM's transparency and communication vis-à-vis market participants, the BM has approved a long-term monetary policy strategy document clarifying the money targeting framework, defining a new format for the monetary policy committee, and specifying its communication policies. The central bank has also made good progress in increasing its analytical capacity through the development of databases and the use of standard monetary models to assess the appropriateness of the monetary policy stance. Work is ongoing to translate the annual and quarterly monetary targets into a liquidity management plan that separates the management of short-term "temporary" and long-term "structural" liquidity resulting from government domestic expenditures mainly financed through foreign donor inflows. The BM will introduce repos in 2007 to fine-tuning "temporary" liquidity variations, and is working to ensure an "appropriate" mix of foreign exchange sales and net treasury bill issuance to sterilize structural liquidity to facilitate absorption of foreign aid, with clear signaling of sterilization and intervention actions in the foreign exchange market. The deepening of debt and foreign exchange markets will also be needed to avoid undue movement in interest rates and exchange rates.

Central Bank operational independence. Despite the recent recapitalization agreements reached between the BM and the Ministry of Finance, central bank operational independence in conducting monetary policy has yet to be ensured through a more comprehensive agreement to shift the corresponding costs to the Ministry of Finance. In this regard, the two institutions are currently discussing the operational details of specific modalities to be included in a memorandum of understanding expected to be signed by both parties in 2007 .

Central bank liquidity management. The BM is in the process of refining its liquidity monitoring and forecasting with technical assistance from the Fund. Further technical assistance is needed to enhance the BM's capacity to accurately forecast short-term liquidity flows in the financial system and manage "temporary" fluctuations liquidity using appropriate instruments. Of critical importance are improvements in the information provided by the treasury on its daily cash flows and introduction of repos to fine-tune temporary liquidity variations (see above).

Public debt management. Reform is still in its early stages. The government needs to develop a strategy for the management of domestic debt, and the public debt department at the Ministry of Finance will need to be restructured and its staff trained.

Treasury bill and money markets. While recent progress was achieved with the removal of interest caps on T-bill auctions, more needs to be done to promote an active and liquid market for government securities. At the top of the list would be improving the enforcement of the legal framework governing the transfer of securities and the implementation of a real time gross settlement (RTGS) system to foster the development of a secondary market. On the latter, the government has just submitted a draft law on a new national payment system. An analysis of the main obstacles to the development of money and secondary debt markets is expected to be concluded by end-2007. In addition, the BM is also starting to look for alternative secondary debt market models so as to deepen Mozambique's secondary T-bill and T-bond markets.

Foreign exchange markets. Important steps have recently been taken regarding the interbank foreign exchange market (MCI) with the gradual removal of price caps (foreign exchange auctions and $\mathrm{MCI}$ ), and measures to promote the practice of firm quotations among market participants. MCI reforms needs to be pursued further by ensuring the complete removal of any remaining price caps, and the adoption of an appropriate collateral system. 


\section{Box II.8. Strengthening Mozambique's Lending Environment}

Framework for secured transactions. Additional measures include the updating of the legal framework for secured transactions. The recent enactment of a decree on urban land use and corresponding regulations was an initial step in this direction; it is expected to facilitate the use of urban land as a collateral by reducing the time and costs involved in transactions. Next steps in this area would need to tackle the modernization and linking of property registries and the implementation of a new Insolvency and Bankruptcy Law.

Enhancement of the scope and reliability of the credit registry. Reform effort is just starting in this area with assistance from the World Bank- International Finance Organization (IFC) and the Millennium Challenge Corporation (MCC). The BM with assistance from IFC will conduct a feasibility study to examine options to increase the scope and reliability of its credit registry.

\section{Gauging the reform impact}

\section{Financial sector reforms to restructure and strengthen the supervision of} Mozambique's banking system are starting to enhance financial intermediation. While still incomplete, these reforms appear to have contributed to improvements in the soundness of the banking system: nonperforming loans have declined markedly, and bank profitability has recuperated (Figure 2). Greater confidence in the banking system combined with the adoption of prudential measures has led to a significant decrease in financial dollarization
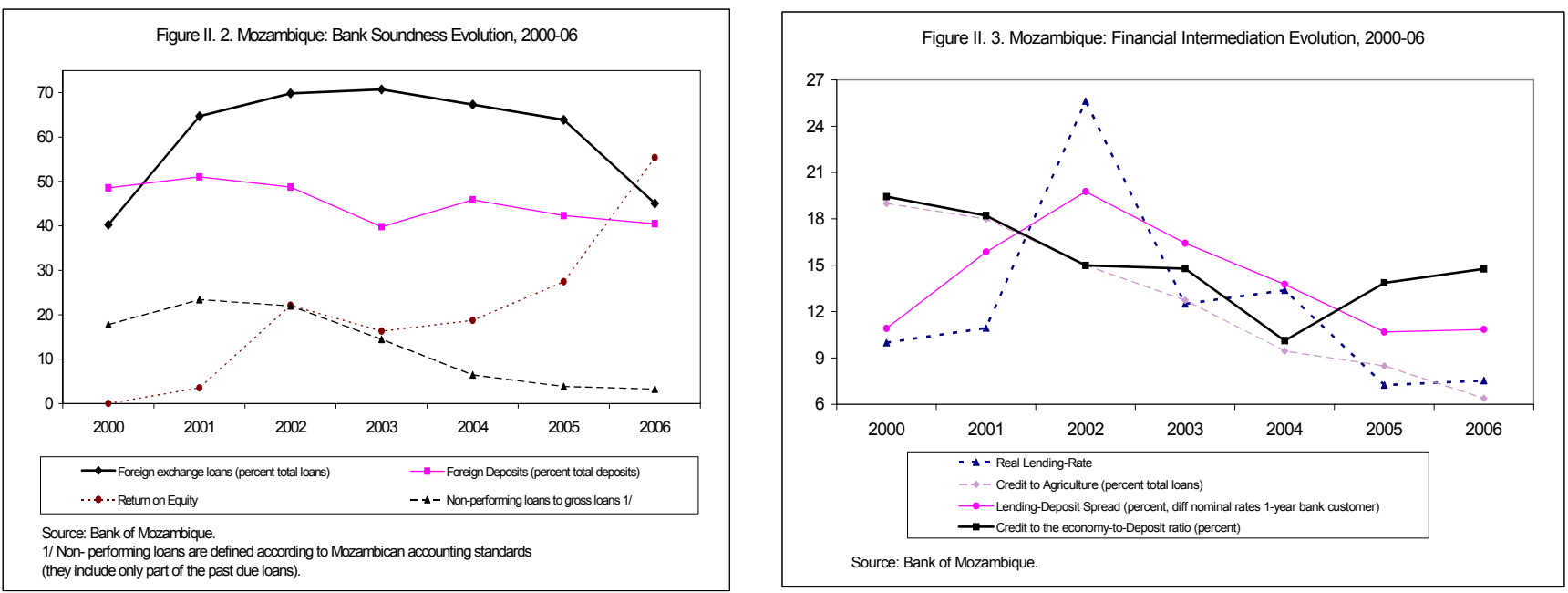
and thus lower financial vulnerability. ${ }^{42}$ Such improvements seem to have presented positive spillovers to financial intermediation (Figure 3). Real lending rates and spreads have been on a declining trend since 2002 with private credit growth starting to pick up more recently, particularly in domestic currency.

\section{Despite some recent improvements, access to affordable credit remains a top}

constraint. Recent business surveys continue to identify the high cost of finance as the top constraint to private sector growth: access to financial services is among the top three constraints (Table 4). Access to finance is also a major constraint to firm growth in Mozambique: more than 70 percent of firms do not have access to a bank loan or to overdraft facilities (the number even higher for small and medium-sized enterprises (SMEs), according to the 2003 ICA and 2006 CTA-MPD survey (World Bank 2003, Ministry of Planning and Development 2006)). Access to credit in the agriculture sector is also an issue, as indicated by its shrinking contribution to total credit (Figure 3) and poor microfinance outreach in rural areas (Box 9). This seems to suggest that some of the most binding constraints to financial intermediation have yet to be tackled.

Table II. 4. Mozambique : Developments in Perceived Constraints

\begin{tabular}{|c|c|c|c|c|c|c|c|c|}
\hline & \multicolumn{3}{|c|}{2002 Survey } & \multicolumn{3}{|c|}{2006 Survey } & \multicolumn{2}{|c|}{ Changes } \\
\hline & Mean 1/ & $\begin{array}{c}\text { Major/Severe } \\
\text { obstacle } \\
\text { (percent) }\end{array}$ & Rank & Mean 1/ & $\begin{array}{c}\text { Major/Severe } \\
\text { obstacle } \\
\text { (percent) }\end{array}$ & Rank & Means & Rank \\
\hline Cost of credit & 3.28 & 84 & 1 & 3.00 & 72 & 1 & -0.28 & 0 \\
\hline Access to domestic credit & 3.08 & 75 & 2 & 2.42 & 58 & 3 & -0.66 & 1 \\
\hline Access to foreign credit & 2.93 & 73 & 3 & 1.55 & 38 & 9 & -1.38 & 6 \\
\hline Electricity & 2.65 & 64 & 4 & 2.06 & 46 & 6 & -0.59 & 2 \\
\hline General corruption & 2.76 & 64 & 5 & 2.11 & 46 & 7 & -0.65 & 2 \\
\hline Macroeconomic instability & 2.75 & 63 & 6 & 2.65 & 63 & 2 & -0.1 & -4 \\
\hline Anti-competitive practices & 2.59 & 60 & 7 & 1.45 & 32 & 14 & -1.14 & 7 \\
\hline Unpredictability of policies & 2.58 & 58 & 8 & 2.03 & 44 & 8 & -0.55 & 0 \\
\hline Tax rates & 2.45 & 55 & 9 & 2.15 & 50 & 4 & -0.3 & -5 \\
\hline Crime, theft and disorder & 2.47 & 54 & 10 & 1.79 & 35 & 11 & -0.68 & 1 \\
\hline Customs & 2.11 & 49 & 11 & 1.70 & 38 & 10 & -0.41 & -1 \\
\hline Tax administration & 2.19 & 48 & 12 & 1.74 & 35 & 12 & -0.45 & 0 \\
\hline Labor Regulations & 1.80 & 38 & 13 & 2.07 & 48 & 5 & 0.27 & -8 \\
\hline Skills/education of workers & 1.79 & 34 & 14 & 1.68 & 35 & 13 & -0.11 & -1 \\
\hline Business registration & 1.44 & 28 & 15 & 0.86 & 10 & 18 & -0.58 & 3 \\
\hline Transportation & 1.43 & 27 & 16 & 1.44 & 26 & 15 & 0.01 & -1 \\
\hline Access to land & 1.24 & 27 & 17 & 0.82 & 18 & 16 & -0.42 & -1 \\
\hline Telecommunications & 1.28 & 20 & 18 & 0.76 & 14 & 17 & -0.52 & -1 \\
\hline
\end{tabular}

Souce: MPD (2006).

Note: 1/ Average across firms of judgements on how much listed factors constrain the

operation and growth of their business; where $0=$ no obstacle, $1=$ slight, $2=$ moderate, $3=$ major;

and $4=$ serious obstacle.

\footnotetext{
${ }^{42}$ The strong decline in credit in foreign currency was particularly driven by the implementation of a prudential measure to provision 50 percent of foreign-currency denominated loans to nonexporters introduced in July 2005 (Notice 5/2005). This decrease was, however, accompanied by an increase in applications for private external financing.
} 


\section{Box II.9. Microfinance in Mozambique}

The microfinance sector has grown markedly in the past decade. Growth both in the number of clients and, especially in the outstanding loan portfolio was considerable (about a five and seven-fold increase from 2000 to 2005). Consolidation also seems to be underway: three institutions out of about thirty-five control more than 68 percent of the active loan portfolio. There are also some indications of institutional growth, meaning that the number of MFIs with higher client numbers has grown. In 1998 there were only two operators with more than 1,000 clients. By 2005 half the MFIs had more than 1,000 clients. Growth has also been accompanied by a substantial improvement in performance. The percentage of MFI with recovery rates considered acceptable (90 percent or above) increased from 16 percent in 1997 to about 30 percent in 2005.

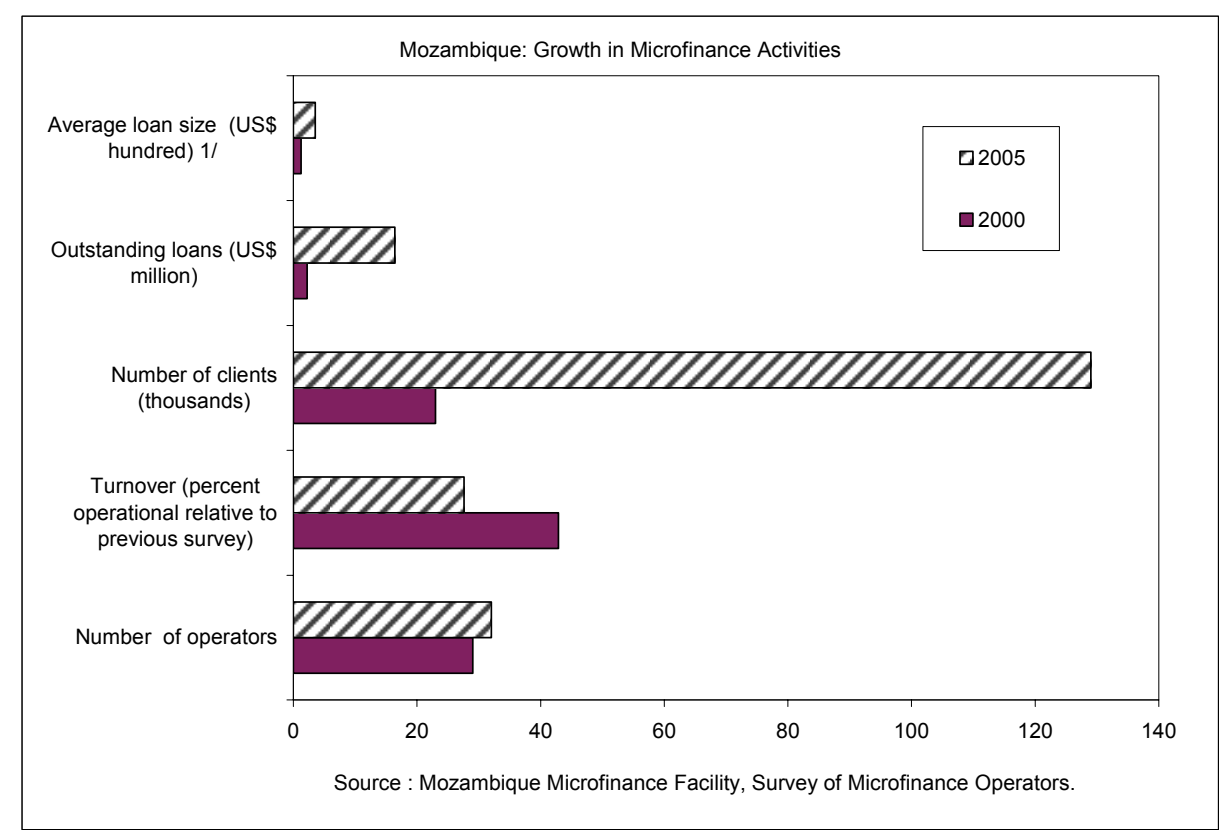

However, MFIs' outreach, particularly in rural areas remains very limited. About 62 percent of MFIs and 50 percent of microborrowers are concentrated in the Maputo-Matola urban corridor: rural areas account for less than 12 percent of borrowers and only 5 percent of the total active portfolio. To some extent, this disparity in microfinance provision seems to reflect the large concentration of nonagricultural informal activities in the province of Maputo or Maputo City. Preliminary data for 2005 on informal sector activities published by Mozambique's national statistical agency show that of the nonagricultural informal sector activities, 42 percent of those involved in trading and 48 percent of those involved in services (excluding transport) are located in those areas.

45. While broadly in line with identified priorities, reform implementation in some areas needs to be intensified. Emphasis has been rightly placed on finalizing the banking restructuring process and improving banking supervision. However, the prevalence of the high cost of, and limited access to, credit among SMEs, and limited credit growth in the 
agriculture sector seems to indicate the need to step up reform efforts to improve the institutional lending environment, as well as measures to improve banks and MFI outreach in rural areas. The pace of reforms in monetary and public debt management, while satisfactory overall, have been slower than envisaged, in the areas of liquidity and public debt management. As a result, interbank and secondary markets remain shallow, limiting the effectiveness of monetary policy and the pace of capital market development. The next section flags the positive aspects of the reform strategy that could usefully be preserved and disseminated as lessons, as well as challenges that need to be confronted to further strengthen the strategy's effectiveness.

\section{E. Strengthening the Strategy: Lessons and Challenges}

46. There is scope to further strengthening Mozambique's reform strategy. This section identifies lessons learned and some near term challenges. It will serve mostly as groundwork for a more comprehensive assessment envisaged for 2008, which will encompass a planned FSAP update along with the FSTAP midterm review. Mozambique's financial sector strategy will be revised on the basis of these assessments with a particular focus on accelerating financial sector development.

\section{Lessons learned}

47. Mozambique's financial sector reform strategy by rightly addressing the key weaknesses in the design and implementation of reforms in low-income countries has some important lessons to offer.

- Getting diagnostics and priorities right is an important starting point. Obstacles to financial sector development abound in low-income countries. As such, countries would benefit by making full use of recent diagnostics exercises in the design of the reform strategies, paying particular attention to the proposed prioritization. This strategy has paid off in Mozambique, where the proposed financial sector reform strategy has taken full advantage of the diagnostics, and recommendations of a preceding FSAP. In particular, FSAP- proposed prioritization has allowed for targeted and more effective interventions, thus building the political capital of reformers and thus reform momentum.

- $\quad$ Close attention needs to be paid to institutional arrangements that ensure government ownership and coordination of the reform process. Mozambique's

financial sector reform strategy has taken into account the transaction and accountability costs of implementing reforms in an environment with multiple financiers on one side, and government beneficiaries, on the other. While the FSTAP stops short of being financed by a common fund, there is a clear division of labor, and financing responsibilities among donors regarding reform areas. Moreover, the 
adoption of a common implementation unit to deal with aspects related to procurement, monitoring, and evaluation of all projects further contribute to donor coordination and reduced transaction costs. In addition, making the unit directly accountable to a single government ministry but responsive to a committee of all beneficiaries strengthened government ownership while promoting intragovernmental coordination.

- $\quad$ Capacity building is an essential element to sustain the reform process. The success and sustainability of reform programs depend to a large extent on local capacity to analyze issues and to redesign and implement strategies in the face of changing circumstances. The FSTAP takes that into consideration by including capacity building measures in each of its components.

- Measuring performance is also key. The availability of easily measurable outcomes is essential to gauge the reform progress, identify reform bottlenecks, and ensure accountability. Mozambique's results framework has been particularly useful in this regard.

\section{Challenges ahead}

48. Improving access to affordable finance remains a key challenge. With the soundness of the banking system restored, reforms to improve financial sector intermediation and access to financial services are assuming center stage. Policies and reforms in this area will need to continue to strengthen the lending environment and facilitate the outreach of banks and MFIs and other privately provided financial services to SMEs and rural areas. In this regard, the recently announced rural financing strategy is particularly welcomed. Reflecting a satisfactory consultative process with banks, it tackles some of the main impediments to bank branch development, including less stringent reserve requirements. Looking ahead, it would be important to identify new quick wins. In this regard, special attention could be given to credit registries, particularly by expanding their scope and making sure that their coverage increases in line with outreach growth. ${ }^{43}$ The alternative of using leasing and factoring agreements could also be explored.

\section{Capacity building and human resource mobilization would need to keep pace} with reforms to strengthen monetary policy formulation and deepen monetary and public debt markets. Reforms to improve the efficiency of primary debt markets, and reduce segmentation in the interbank market with the introduction of repo operations could

\footnotetext{
${ }^{43}$ Expanding the scope and coverage of credit registries have usually been regarded as less controversial than reforms to bankruptcy or property laws. It has also emerged as a partial substitute for institutions ensuring creditor rights (Djankov et al 2006).
} 
be accelerated. Along with the implementation of a RTGS system, such pacing would help deepen the market for government securities, thus establishing a benchmark for future capital market development. Capacity building and resource mobilization at the BM and Ministry of Finance will remain a main priority in the near term so that participants can tap deepening monetary and debt markets. At the BM this will require the permanent mobilization of resources towards policy and operations so as to (i) systematically assess the monetary stance and select the appropriate mix of instruments, (ii) conduct repo transactions, and (iii) communicate and justify BM's actions to market participants in a transparent way. Capacity building could also be enhanced at the Ministry of Finance, where the public debt department needs to be reorganized, and its staff trained with a view to strengthen information and analysis reporting.

\section{Supervision and accounting standards need to be strengthened beyond the} banking sector to ensure the soundness of an expanding financial system. In the near term, introduction of risk-based supervision and international reporting standards in the banking sector will facilitate monitoring of capital adequacy during a period of strong credit growth. Rolling out IFRS standards to the corporate sector will further reduce credit risk by improving the ability of the financial system to evaluate the quality of their loan portfolios. Looking ahead, the sustainability of the national pension fund needs to be secured through a restructuring based on an actuarial study. A strengthening of the supervisory framework for the growing nonbank financial sector is becoming more important. In this area, special attention could be given to microfinance and other institutions catering to the poor and unbanked. The regulatory and supervisory framework will need to continue to strike a balance between ensuring soundness and sustainability without compromising growth and outreach.

\section{Preserving the positive institutional features of the reform strategy will also be}

key to keep the reform momentum. In this regard, it will be important to ensure that the FSTAP remains the umbrella under which financial sector reforms are conducted in Mozambique. In the same vein, government and donors would benefit by fully relying on the FSTAP implementation arrangements when pursuing new initiatives. In particular, rather than transferring the Micro and Rural Finance component from the FSTAP to the IFAD project, the government could usefully consider increasing the coordination and sharing of information among these two projects. Equally beneficial would be the integration of the IFC-MCC project on credit registry to the FSTAP so as to avoid a duplication of implementation and monitoring arrangements and the increasing transactions costs they entail. 


\section{Appendix. FSTAP Action Plan}

Table II. A. Mozambique: FSTAP Results Framework Matrix - Selected Key Actions 1/

\begin{tabular}{|c|c|c|c|c|}
\hline \multirow{2}{*}{ Program Components } & \multicolumn{4}{|c|}{ Program Outcomes } \\
\hline & 2007 & 2008 & 2009 & 2010 \\
\hline \multirow{2}{*}{$\begin{array}{l}\text { 1) Enhanced capacity of the } B M \text { in terms of banking supervision and provision of } \\
\text { financial infrastructure }\end{array}$} & $\begin{array}{l}50 \text { percent of banks in compliance with } \\
\text { improved prudential regulations; and }\end{array}$ & & $\begin{array}{l}80 \text { percent of banks in compliance with improved } \\
\text { prudential regulations. }\end{array}$ & $\begin{array}{l}100 \text { percent of banks in compliance with improved } \\
\text { prudential regulations; and }\end{array}$ \\
\hline & $\begin{array}{l}\text { BM compliant with } 16 \text { out of } 23 \text { Basel Core } \\
\text { Principles. }\end{array}$ & & & BM compliant with all Basel Core Principles. \\
\hline \multirow[b]{2}{*}{ 2) Improved financial accountability and transparency } & $\begin{array}{l}\text { Timetable for the implementation for IFRS } \\
\text { adopted; and }\end{array}$ & $\begin{array}{l}90 \text { percent of banks' financial reporting IFRS } \\
\text { compliant. }\end{array}$ & $\begin{array}{l}100 \text { percent of banks' financial reporting IFRS } \\
\text { compliant; and }\end{array}$ & $\begin{array}{l}75 \text { percent of large enterprises' financial reporting } \\
\text { IFRS compliant 2/; and }\end{array}$ \\
\hline & $\begin{array}{l}\text { New regulations on assessment, classification } \\
\text { and provision, and on integral risk management } \\
\text { becomes effective. }\end{array}$ & & & $\begin{array}{l}20 \text { percent of medium enterprises financial reporting } \\
\text { IFRS compliant. }\end{array}$ \\
\hline \multirow{3}{*}{ 3) Strengthened public debt management capacity } & $\begin{array}{l}\text { Strengthen staff complement, consolidate debt } \\
\text { database; }\end{array}$ & $\begin{array}{l}\text { Annual publication of public debt reports including } \\
\text { comprehensive debt inventory; and }\end{array}$ & & \\
\hline & Public debt report published; and & & & \\
\hline & Regular debt forecasts first published. & Semiannual publication of debt forecasts. & & Quarterly publication of debt forecasts. \\
\hline 4) Improved money and government bond market efficiency and depth & $\begin{array}{l}\text { Implementation of a master repurchase } \\
\text { agreement and program. }\end{array}$ & & Treasury security auctions held on a monthly basis. & \\
\hline \multirow{4}{*}{$\begin{array}{l}\text { 5) Improved financial intermediation through a strengthened micro and rural } \\
\text { sector integrated into the financial system }\end{array}$} & $\begin{array}{l}\text { Gap analysis for MFI training conducted and } \\
\text { training strategy in place; }\end{array}$ & $\begin{array}{l}\text { New regulation for the operation and supervision } \\
\text { of MFIs developped; }\end{array}$ & $\begin{array}{l}\text { Development and introduction of innovative } \\
\text { financial products. }\end{array}$ & \\
\hline & Microfinance Association operational; & Number of Licensed microfinance institutions; $3 /$ & & \\
\hline & $\begin{array}{l}\text { IFRS adopted by all large MFIs (microbanks); } \\
\text { and }\end{array}$ & Access of all large MFIs to payment system; and & & \\
\hline & FinScope study initiated. & FinScope study concluded. & & \\
\hline 6) Strengthened regulatory and supervisory regime for the insurance industry & $\begin{array}{l}\text { New prudential regulations and a supervisory } \\
\text { framework implemented. }\end{array}$ & & Insurance companies adopt IFRS. & $\begin{array}{l}\text { Insurance premiums as a percentage of GDP at } 3 \\
\text { percent. }\end{array}$ \\
\hline \multirow{2}{*}{ 7) Modernized and efficiently administered social security system } & New pension fund legislation approved; and & $\begin{array}{l}\text { Recommendations on improving social security } \\
\text { coverage implemented; and }\end{array}$ & & $\begin{array}{l}\text { Number of registered participants of INSS reaches } 90 \\
\text { percent; and }\end{array}$ \\
\hline & Actuarial study completed. & New organization structure for INSS adopted. & & $\begin{array}{l}\text { Number of active contributors of INSS reaches } 60 \\
\text { percent of participants by } 2010 \text {. }\end{array}$ \\
\hline \multirow[b]{2}{*}{ 8) Improved legal and judicional environment for lending } & $\begin{array}{l}\text { New laws on insolvency and property registries } \\
\text { enacted; and }\end{array}$ & & $\begin{array}{l}\text { Credit Registry expanded to include all providers of } \\
\text { credit; and }\end{array}$ & \\
\hline & $\begin{array}{l}\text { New commercial sections created in the } \\
\text { Judicial Tribunals of the City of Maputo, and } \\
\text { Provinces of Beira and Nampula. }\end{array}$ & & $\begin{array}{l}\text { All property registries computerized and } \\
\text { electronically linked. }\end{array}$ & \\
\hline \multirow{2}{*}{ 9) Establishment of a financial information center to investigate financial crimes } & $\begin{array}{l}\text { New law on the Financial Information Center of } \\
\text { Mozambique enacted; and }\end{array}$ & & & \\
\hline & $\begin{array}{l}\text { Financial Information Center established and } \\
\text { fully functional. }\end{array}$ & & & \\
\hline
\end{tabular}

Source : World Bank (2005).

$1 /$ Please refer to source for a complete description of the results framework matrix

2/ Large (medium) enterprise is defined as a company with greater than 1,000 $(250-1,000)$ employees.

$3 /$ Sequencing and targets on Component Five were not determined. 


\section{References}

Barth, James R., Gerard Caprio, Jr., and Ross Levine, 2004, "Bank Regulation and Supervision: What Works Best?," Journal of Financial Intermediation, Vol.13, pp. 205-248.

Boyd, John H., Ross Levine, and Bruce D. Smith, 2001, "The Impact of Inflation on Financial Sector Development," Journal of Monetary Economics, Vol. 47, pp. 221248.

Djankov, Simeon, Caralee McLiesh, and Andrei Shleifer, 2006, "Private Credit in 129 Countries," forthcoming at Journal of Financial Economics. Available at http://www.doingbusiness.org/documents/private credit jan23.pdf

International Monetary Fund, 2006, World Economic Outlook, September 2006 (Washington: International Monetary Fund).

Levine, Ross, 2005, Finance and Growth: Theory and Evidence, in Aghion, P. and Durlauf, S. (eds), Handbook of Economic Growth, pp. 865-934 (Amsterdam: Elsevier, North Holland).

Ministry of Planning and Development, Government of Mozambique (MPD), 2006, Enterprise Development in Mozambique: Results based on Manufacturing Surveys conducted in 2002 and 2006, Discussion Paper N 33E, October, National Directorate of Studies and Policy Analysis (Maputo: National Directorate of Studies and Policy Analysis).

World Bank, 2003, Mozambique Industrial Performance and Investment Climate 2003 (Washington: World Bank).

World Bank, 2005, Financial Sector Technical Assistance Project. Project Appraisal Document (Washington: World Bank).

World Bank, 2007, “Cost of Doing Business Report” (Washington: World Bank). 


\section{Trade Policy in Mozambique: An Overview ${ }^{44}$}

\section{A. Introduction}

\section{Trade policies have recently been acknowledged as an important driver of} sustainable growth episodes. Trade liberalization can both accelerate and sustain growth, particularly when accompanied by a competitive exchange rate (Berg, Ostry, and Zettelmeyer 2006) and preceded by reforms to streamline burdensome regulatory environments (Bolaky and Freund 2004). This recipe has been proven particularly successful in East Asian countries where policies to avoid over-valued exchange rates and reduce regulatory trade costs have played an important role in facilitating and sustaining their growth take-offs (Johnston, Ostry, and Subramanian 2007). These results suggest that it is important to take a broad look at a country's trade policy options, with a view to determine how such policies should be prioritized in the context of globalization and regionalism.

\section{This paper analyzes Mozambique's trade policy options using a simple}

framework focused on creating an environment to promote external trade. This simple qualitative framework reduces Mozambique's trade policy options into two categories: those that improve Mozambique's external competitiveness and those that enhance its market access. Reforms to enhance competitiveness by reducing the regulatory burden of Mozambique's business environment are proposed as the main policy priority. A stronger business environment is shown to not only improve competitiveness directly by reducing the costs of doing business, but also to have important indirect effects by allowing unilateral trade liberalization to effectively improve firm-level competitiveness and market access opportunities to be securely tapped. The paper is organized as follows: Section B presents the key concepts and introduces the framework proposed to evaluate Mozambique's trade policy options. Section C discusses Mozambique's policy record in addressing competitiveness. Section D examines market access issues. Section E summarizes the main conclusions.

\section{B. Trade Policy Options}

\section{Competitiveness: macro and micro perspectives}

\section{Both macro and microeconomic factors need to be taken into consideration} when analyzing a country's external competitiveness. ${ }^{45}$ Common measures of macroeconomic competitiveness are the real effective exchange rate (REER) and changes in a country's export share in the world market. These measures, however, are limited for several reasons. First, a country's share of exports in the world market could result from distortionary policies in the form of subsidies or a manipulation of the exchange rates aiming to capture a higher export share. Second, the macroeconomic perspective fails to take into account microeconomic factors, such as custom procedures and the regulatory environment,

\footnotetext{
44 Prepared by Eteri Kvintradze.

${ }^{45}$ External competitiveness is defined here as the ability to offer a conducive trade environment.
} 
which, through their effects on the cost structure of firms, have direct implications for external competitiveness, even when exchange rate policies are deemed appropriate. ${ }^{46}$ The microeconomic perspective of competitiveness emphasizes the importance of the overall business environment in which the firms operate, including the importance of tariff and nontariff barriers. ${ }^{47} \mathrm{~A}$ strong business environment promotes competitiveness by allowing countries to trade efficiently. The government's role is thus to ensure that all economic agents have fair and comparable conditions (a level playing field).

\section{A weak business environment can hurt trade even when the trade regime is}

deemed appropriate. For example, broad-based multilateral trade liberalization, which reduces tariff and nontariff barriers to imports, can reduce input costs and improve how efficiently firms allocate resources. Such liberalization alone, however, is not enough to improve firms' competitiveness. The speed with which less efficient firms exit and more efficient firms enter the liberalized domestic market is also crucial. ${ }^{48}$ For example, if protectionist policies or a poor business environment keep inefficient firms from exiting or more efficient businesses from entering the market, then competitiveness is not likely to improve very much. ${ }^{49}$

\section{Market access}

56. Market access refers to the ability of domestic providers of goods and services to sell in foreign markets. Two parties participate in international trade: the country in question and the rest of the world. Thus, trade outcomes depend on not only the trade policies of the country in question toward other countries as well as the trade policies of the rest of the world as they relate to that country formalized under alternative trade agreements. A country and the rest of the world enter into trade agreements on a bilateral, regional, and/or multilateral basis. In general, these agreements reduce market access barriers partners face in accessing each other's markets, such as: (i) tariffs and other price-based border measures; (ii) nontariff border measures (e.g., quantitative restrictions, contingency measures, technical

\footnotetext{
${ }^{46}$ As discussed in USAID (2006).

${ }^{47}$ In this sense, it is different from a static concept of comparative advantage, which looks into factor endowments, as discussed in Porter (1998).
}

${ }^{48}$ See Bernard, Redding, and Schott (2007).

${ }^{49}$ Governments protect some businesses for various reasons. Infant businesses are protected to help them reach their competitive potential. Strategic businesses may be protected because of their location in postconflict zones or underdeveloped regions where they are the main source of social welfare. Other businesses can be protected because they successfully lobby their interests. The literature on the political economy of trade analyzes the effects of interest group lobbying on trade policy. For example, a number political economy models of trade with heterogeneous firms, have found that sectors with more concentrated factor ownership are better able to secure favorable protection, than those with less concentrated factor ownership. See Grossman and Helpman (2002) for a survey of the literature. 
barriers to trade, and sanitary measures); and (iii) domestic policy measures (e.g., government policies, which may favor some sectors if not applied uniformly to all imported inputs and exported final products). ${ }^{50}$ From an individual country's perspective, gaining greater market access to foreign markets depends on the negotiating power and skills of the incumbent government and the collective interests of other members of these trade agreements.

\section{A simple analytical framework}

57. A simple two-dimensional analytical framework can be used to identify trade policy constraints and propose trade policy priorities. Trade policy constraints and priorities are divided into those impacting external competitiveness and those affecting market access. External competitiveness includes policies to lift trade barriers and strengthen the business environment, whereas market access involves the establishment of regional, bilateral or multilateral trade agreements.

\section{Under this simple framework, a government must first determine whether trade} is restricted and if so, identify what factors are driving trades below potential. As shown in Figure 1, trade is not restricted in a country that has (i) an environment that is conducive to trade and (ii) access to foreign markets (outcome 1). In all other cases $(2,3$, and 4$)$ trade is deemed restricted. Under each of these cases, a different policy action is required: gaining access to key markets to utilize competitive potential (2); addressing (macro and micro) competitiveness constraints to utilize market access opportunities (3); and addressing both market access and competitiveness constraints (4). It is important to note that under case 3 , policy actions to address competitiveness issues are under the full control of the government, while gaining market access to foreign markets is conditional on foreign trade policies and the negotiating power of the government (policy actions needed in cases 2 and 4 , respectively). ${ }^{5}$

\footnotetext{
${ }^{50}$ As discussed in IMF (2002).

${ }^{51}$ We are considering a general two-dimensional analytical framework at a country level. The same framework could be applied at the sector or at the firm level in order to determine the degree of competitiveness or market access constraints. Therefore, this framework could help to define a specific reform strategy addressing sectorspecific constraints.
} 
Figure III. 1. Analytical Framework: Trade Policy Choices

\begin{tabular}{|c|l|l|}
\hline Competitiveness & \multicolumn{1}{|c|}{ Yes } & \multicolumn{1}{|c|}{ No } \\
\hline Yes & $\begin{array}{l}\text { Outcome (1): Trade is not } \\
\text { restricted }\end{array}$ & $\begin{array}{l}\text { Outcome (2): Trade is restricted } \\
\text { Policy: Need to address market access } \\
\text { constraints }\end{array}$ \\
\hline No & $\begin{array}{l}\text { Outcome (3): Trade is restricted } \\
\text { Policy: Need to address } \\
\text { competitiveness constraints in } \\
\text { order to utilize market access } \\
\text { opportunities }\end{array}$ & $\begin{array}{l}\text { Outcome (4): Trade is restricted } \\
\text { Policy: Need to address both market access } \\
\text { and competitiveness constraints }\end{array}$ \\
\hline
\end{tabular}

\section{Evaluating Competitiveness}

\section{This section evaluates the competitiveness of Mozambique's economy from the} macroeconomic and microeconomic perspectives. From the macroperspective, we analyze export shares in world trade and the terms of trade. ${ }^{52}$ From the microperspective, we look at tariff and nontariff barriers, domestic policies, and the business environment Mozambique's overall external competitiveness is shown to be constrained by a weak business environment and protectionist policies.

\section{Macroperspective}

60. Mozambique's world export shares and terms of trade have grown markedly in recent years. Its average share of world exports more than doubled in 2001-06, more than the average for sub-Saharan African (SSA) and ASEAN 4 countries (Table 1). ${ }^{53}$

Mozambique's terms of trade improved on average by nearly 7 percent a year in 2001-06, up from 0.5 percent in 1991-2000, mainly because prices for aluminum, its primary export, rose more than prices on imports beginning in 2003.

\footnotetext{
${ }^{52}$ An updated assessment of competitiveness from a macroperspective on the basis of REER is conducted in Box 1 of the accompanying staff report. Mozambique's REER is shown to have been relatively stable over the past decade. However, econometric results presented suggest that the REER may be overvalued by about 10 percent, though with some statistical uncertainty about the precise magnitude. As such, Mozambique's external competitiveness may have been stronger had its REER been aligned with its underlying equilibrium rate.

${ }^{53}$ Throughout this chapter, ASEAN 4 countries (Indonesia, Malaysia, Philippines, and Thailand) will be used as benchmarks given their successful sustainable export-led growth experiences.
} 
Table III.1. Mozambique: Share in World's Exports and Terms of Trade

\begin{tabular}{lccccc}
\hline & \multicolumn{2}{c}{ Share in World's Exports } & & \multicolumn{2}{c}{ Terms of Trade Growth } \\
\cline { 2 - 3 } \cline { 6 - 7 } & $1991-00$ & $2001-06$ & & $1991-00$ & $2001-06$ \\
\hline \multirow{3}{*}{ Mozambique } & 0.01 & 0.02 & & 0.5 & 6.9 \\
SSA & 1.5 & 1.64 & & -0.2 & 4.9 \\
ASEAN 4 & 3.52 & 3.51 & & 0.6 & 0.4 \\
\hline
\end{tabular}

Source: IMF staff estimates and projections.

61. Mozambique's strong export performance, however, almost exclusively reflects megaproject-related exports most notably aluminum, rather than broad-based competitiveness gains. ${ }^{54}$ Mozambique revealed comparative advantage is in the production of aluminum, gas, and wood articles (Table 2). ${ }^{55}$ All megaproject exports (electricity, aluminum, and gas) accounted for more than 70 percent of total exports in 2006; aluminum alone accounted for 58.6 percent of the total. Traditional exports grew by an average 4 percent a year, while mega-project exports grew by 10.4 percent. Megaproject-related imports as a share of total imports hovered around 20 percent (Figure 2). Excluding megaproject exports, the contribution of the export sector to the economy has remained fairly stable. Since 2000, the year the aluminum smelter factory Mozal reached full capacity, megaproject-related exports have surged. In 2004, Mozal's exports accounted for 72 percent of total exports.

Table III.2. Mozambique: Export Profile

\begin{tabular}{|c|c|c|c|c|c|c|}
\hline & \multicolumn{2}{|c|}{ Share in Total } & \multicolumn{2}{|c|}{ Share in World Exports } & \multicolumn{2}{|c|}{ RCA 1/ } \\
\hline & 2000 & 2004 & 2000 & 2004 & 2000 & 2004 \\
\hline & \multicolumn{2}{|c|}{ (percent) } & \multicolumn{2}{|c|}{ (percent) } & & \\
\hline All products & 100 & 100 & 0.006 & 0.017 & n.a. & n.a. \\
\hline Aluminium & 16.52 & 72.87 & 0.094 & 1.167 & 1.02 & 1.03 \\
\hline Fish & 27.37 & 6.09 & 0.250 & 0.173 & 0.63 & 0.58 \\
\hline Mineral Fuels, Gas & 20.99 & 4.06 & 0.012 & 0.006 & 10.32 & 10.63 \\
\hline Wood articles & 3.92 & 2.6 & 0.022 & 0.041 & 1.05 & 1.05 \\
\hline Tobacco & 2.14 & 2.6 & 0.037 & 0.167 & 0.34 & 0.26 \\
\hline Cotton & 7.09 & 2.36 & 0.075 & 0.054 & 0.55 & 0.73 \\
\hline Sugar & 1.18 & 1.74 & 0.032 & 0.113 & 0.22 & 0.25 \\
\hline Others & 20.79 & 7.68 & n.a. & n.a. & n.a. & n.a. \\
\hline
\end{tabular}

Source: COMTRADE.

1/ Revealed comparative advantage.

\footnotetext{
${ }^{54}$ Megaprojects' economy wide spillovers to the rest of the economy remains subdued by their capital intensive nature, profit repatriation patterns, limited vertical and horizontal linkages to the economy, and reduced fiscal contribution. See Box 1, IMF Country Report No. 06/46 for additional information.

${ }^{55}$ Revealed comparative advantage is the ratio of the product's share in country exports to its share in world exports. If that ratio is greater than one, the country is said to have a revealed comparative advantage in that product.
} 


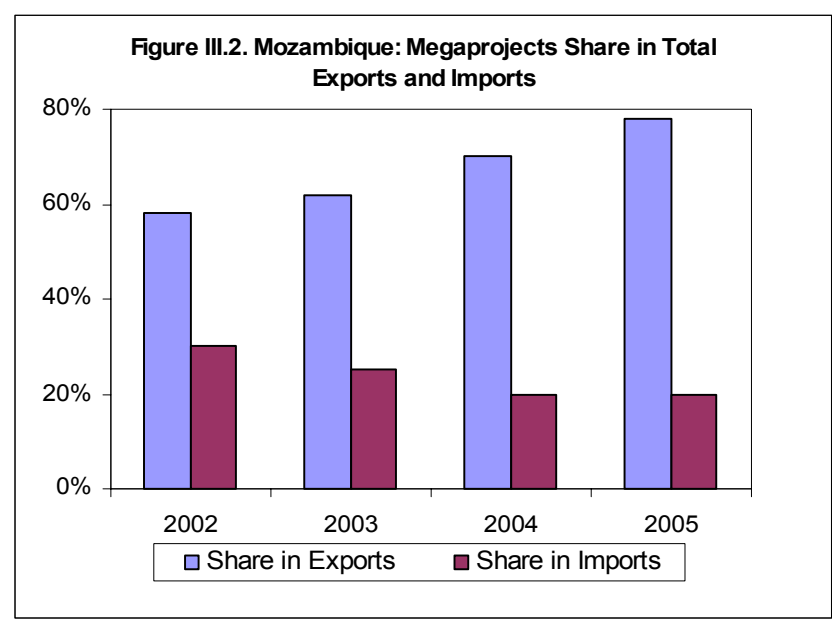

Source: IMF staff estimates, and projections.

\section{Microperspective}

\section{Protectionist domestic policies}

\section{Mozambique's trade patterns have been strongly influenced by favorable} domestic policies for megaprojects. Besides favorable trading terms and tax exemptions, many megaprojects qualify as export-processing zones (EPZ), which allow manufacturers to import goods duty free, offer on-site customs facilities, and carry tax incentives. For example, Mozal, which is an EPZ, is exempt not only from customs duties on imported inputs, but also from real property, value-added, and specific consumption taxes. Nineteen manufacturing factories in Mozambique benefit from EPZs, including Mozal, Moma, a large mining company, and a number of textile manufacturing, tires, and engineering firms. ${ }^{56}$

\section{Protections for the sugar and cashew industries have also shaped trade patterns.} In the late 1990s, to protect what were then infant industries, Mozambique introduced an export tax on raw cashew (18 percent) and an import tax on sugar ( 25 percent), measures that are still in place. The import tax on sugar was introduced as a condition of large-scale foreign investment in the sugar estates located in remote areas with few other income opportunities. ${ }^{57}$ As a result of these protective measures, the production capacity and output of sugar mills increased significantly. An export tax on unprocessed cashew was also introduced to help the newly privatized cashew sector adjust to international competition and after the government abolished the price control. Currently, the export tax penalizes small-size raw cashew nut exporters and stimulates small and medium-size labor-incentive cashew nut processing factories.

\footnotetext{
${ }^{56}$ Firms must employ at least 250 permanent Mozambique workers to qualify as a stand-alone EPZ.

${ }^{57}$ Investment in the sector came mostly from South Africa and Mauritius.
} 
64. Mozambique's trade regime is not excessively restrictive. Its tariff structure is relatively simple: import tariffs fall into four nonzero bands $(2.5,5,7$, and 20 percents). According to overall ratings of trade restrictiveness, Mozambique's trade barriers (tariff and nontariff) are lower than all neighboring countries (Tanzania, Malawi, Zimbabwe, South Africa, and Swaziland) and most ASEAN countries (Table 3). Its trade-weighted average tariff is 9.1 percent, among the lowest in SSA, though the simple average tariff (12.1) percent is higher than most other SSA countries (Table 4) as a result of high tariffs in certain import categories with low import levels. ${ }^{58}$ Thus, reducing the maximum tariff band further could eliminate the latter restriction on trade. ${ }^{59}$ In particular, a reduction of the maximum tariff rate by 5 percentage points, else equal, has been shown to lower Mozambique's simple average tariff from 12 to 10 percent bringing it closer to the current trade-weighted average tariff level.

Table III.3. Mozambique: Tariff and Non Tariff Barriers, 2006

\begin{tabular}{lccc}
\hline & $\begin{array}{c}\text { Trade Restrictiveness } \\
\text { Overall Rating }\end{array}$ & $\begin{array}{c}\text { Tariff Barriers } \\
\text { Rating }\end{array}$ & $\begin{array}{c}\text { Non-Tariff Barriers } \\
\text { Rating }\end{array}$ \\
\hline Angola & 1 & 1 & 1 \\
Congo DRC & 2 & 2 & 1 \\
Madagascar & 2 & 2 & 1 \\
Mozambique & 2 & 2 & 1 \\
Zambia & 2 & 2 & 1 \\
Mauritius & 4 & 1 & 2 \\
Botswana & 5 & 2 & 2 \\
Lesotho & 5 & 2 & 2 \\
Namibia & 5 & 2 & 2 \\
South Africa & 5 & 2 & 2 \\
Swaziland & 5 & 2 & 2 \\
Tanzania & 5 & 2 & 2 \\
Zimbabwe & 6 & 3 & 2 \\
Indonesia & 5 & 1 & 2 \\
Malaysia & 4 & 1 & 2 \\
Thailand & 4 & 2 & 2 \\
\hline
\end{tabular}

Source: IMF staff estimates and projections.

\footnotetext{
${ }^{58}$ A simple average tariff is calculated by adding up all tariff rates and dividing it by the number of import categories. The simple average tariff may overstate the degree of protectionism in the economy, if a country trades mostly in a few categories with low tariffs, but has high tariff in categories that it would not find advantageous to import. The trade-weighted average tariff avoids this problem by dividing the total tariff revenue by the total value of imports. Thus, if a country has import categories with high tariff rates but low imports in these categories, the trade-weighted average tariff will be lower than the simple average tariff.
}

${ }^{59}$ Mozambique has gradually reduced its maximum tariff, from 35 percent in 1999, to 25 in 2002, to 20 percent in 2006 . 


\begin{tabular}{lcc}
\hline & Trade Weighted & \\
& Average & $\begin{array}{c}\text { Simple Average } \\
\text { Tariff }\end{array}$ \\
\hline Mauritius & 2.2 & 3.1 \\
Angola & 5.4 & 7.2 \\
South Africa & 5.8 & 7.7 \\
Tanzania & 8.1 & 12.7 \\
Mozambique & 9.1 & 12.1 \\
Madagascar & 9.2 & 13.5 \\
Namibia & 9.6 & 7.7 \\
Swaziland & 9.6 & 7.7 \\
Zambia & 9.6 & 13.4 \\
Botswana & 11.1 & 7.7 \\
Lesotho & 16.8 & 7.7 \\
Zimbabwe & 18.0 & 16.2 \\
D.R. Congo & $\ldots$ & 12.0 \\
Indonesia & 6.2 & 7.0 \\
Thailand & 6.2 & 11.9 \\
Malaysia & 4.2 & 7.3 \\
\hline
\end{tabular}

Source: IMF staff estimates and projections.

\section{Mozambique's nontariff barriers are less restrictive than its bordering}

neighbors' (Table 5). According to an absolute ranking of nontariff barriers, besides Mozambique, only a few other SSA countries have less restrictive nontariff barriers than Thailand, Indonesia, and Malaysia. Import permits and import licensing are the most common nontrade barriers. These results, however, must be analyzed with care, because information on nontariff barriers is more complete for ASEAN 4 than for SSA countries.

Table III.5. Mozambique: Types of Non Tariff Barriers and Ratings, 2006

\begin{tabular}{llc}
\hline & Types of Non-Tariff Barriers & Rating \\
\hline Angola & Not apparent & 1 \\
D.R. Congo & Not significant & 1 \\
Madagascar & Not significant & 1 \\
Mozambique & Not significant & 1 \\
Zambia & Not significant & 1 \\
Botswana & Export tax on beer, import permits of agriculture & 2 \\
Lesotho & Permits to protect locally produced goods & 2 \\
Mauritius & Import permits & 2 \\
Namibia & Import permits & 2 \\
South Africa & Protective licensing & 2 \\
Swaziland & Import permits & 2 \\
Tanzania & licensing & 2 \\
Zimbabwe & State trading & 2 \\
& & \\
Indonesia & Affect 10\% imports, 40\% non-oil exports, 30\% production. & \\
& Export tax on rubber, import restrictions and licensing. & 2 \\
Malaysia & Import licensing for about 27\% of tariff lines, export duties & 2 \\
Thailand & Licensing for 26 categories of goods & 2 \\
\hline
\end{tabular}

Source: IMF staff estimates and projections.

Trade liberalization and firm competitiveness

66. Trade liberalization has also contributed to open Mozambique's economy to foreign goods and services (Table 6). The average share of Mozambique's imports in GDP went from 14 percent to 43 percent over the past 15 years, pushing it higher than the average for SSA countries (Table 6). The average share of exports in GDP, while doubling during the 
same period mostly due to megaprojects as mentioned above, remains below the average for SSA and well below the average of ASEAN countries.

Table III.6. Mozambique: Share of Exports and Imports (percent of GDP)

\begin{tabular}{lccccc}
\hline & \multicolumn{2}{c}{ Export to GDP ratio } & & \multicolumn{2}{c}{ Import to GDP ratio } \\
\cline { 2 - 3 } \cline { 5 - 6 } & $1991-00$ & $2001-06$ & & $1991-00$ & $2001-06$ \\
\hline & & & & 38.1 & 43.4 \\
Mozambique & 14.5 & 29.2 & & 29.8 & 32.3 \\
SSA & 28.3 & 32.5 & 52.6 & 59.6 \\
ASEAN 4 & 53.8 & 63.7 & &
\end{tabular}

Source: IMF staff estimates and projections

\section{However, trade liberalization has yet to yield improvements in firm-level}

external competitiveness. Recent enterprise surveys show that in 2002-06 the number of exporting firms increased by only 2 percent, while the number of importing firms increased by 20 percent (Table 7). Indeed, few of the firms surveyed said they had introduced new products or diversified their production (though a number of firms reported that they had improved the utilization of their production capacity).

Table III.7. Mozambique: Results of Firm-level Survey 1/

\begin{tabular}{|c|c|c|}
\hline \multicolumn{3}{|c|}{ (Percent of sample) } \\
\hline & 2002 & 2006 \\
\hline Export & 11.5 & 13.9 \\
\hline Import & 43.2 & 63.9 \\
\hline Diversified production & 78.6 & 60.1 \\
\hline Innovate & 25.5 & 23.4 \\
\hline Capacity utilization improvement & 51.2 & 59.1 \\
\hline
\end{tabular}

Source: MPD, Enterprise Survey, 2006.

1/ 192 firms are included in the 2002 survey and 158 firms in the 2006 survey.

\section{Business environment}

68. Mozambique's business environment is weak. Mozambique must still surpass 53 percent of the countries ranked in the Governance survey and more than 80 percent of the countries listed in the Doing Business survey to reach the top (Table 8). Only four countries in the region have passed the 50 percent mark in the Doing Business survey (with South Africa and Mauritius being the best performers in the SSA group). On average, SSA countries rank worse on the Governance and Doing Business surveys than ASEAN countries.

Table III.8. Mozambique and Comparators : Distance to Top Rank in Business Environment

\begin{tabular}{lcc} 
& Governance & Doing Business \\
\cline { 2 - 3 } Mouth Africa & 0.59 & 0.16 \\
Namitius & 0.22 & 0.18 \\
Botswana & 0.37 & 0.23 \\
Zambia & 0.19 & 0.27 \\
Malawi & 0.55 & 0.58 \\
Lesotho & 0.50 & 0.62 \\
Mozambique & 0.43 & 0.65 \\
Tanzania & 0.53 & 0.79 \\
Madagascar & 0.67 & 0.81 \\
Zimbabwe & 0.48 & 0.85 \\
Angola & 0.93 & 0.87 \\
Thailand & 0.77 & 0.89 \\
Malaysia & 0.63 & 0.10 \\
Indonesia & 0.34 & 0.14 \\
Average for SSA Countries for this sample & 0.20 & 0.77 \\
Average for Asian Countries for this sample & 0.45 & 0.48 \\
\hline
\end{tabular}

Average for Asian Countries for this sample 


\section{Regulatory costs to trade are among the most binding constraints to}

Mozambique's business environment. Benchmarked against SADC and Asian countries, custom procedures and other regulatory costs to trade across borders together with contract enforcement, and business registration stand out among the most important constraints to private sector development in Mozambique (Table 9). In particular, exports of goods must undergo cumbersome evaluation at customs checkpoints. Large firms, which tend to have more resources to draw on, usually do not complain about customs procedures. Small- and medium-size firms, however, find customs procedures burdensome and nontransparent. ${ }^{60}$ More worrisomely, the regulatory environment for trade appears to be deteriorating as indicated by the observed decline in the World Bank's Cost of Doing Business ranking relative to the previous year.

Table III. 9. Mozambique : Cost of Doing Business Rankings, 2006 data 1/

\begin{tabular}{|c|c|c|c|c|c|c|c|c|c|c|c|}
\hline & $\begin{array}{c}\text { Ease of } \\
\text { Doing } \\
\text { Business }\end{array}$ & $\begin{array}{l}\text { Enforcing } \\
\text { Contracts }\end{array}$ & $\begin{array}{l}\text { Starting a } \\
\text { Business }\end{array}$ & $\begin{array}{l}\text { Trading Across } \\
\text { Borders }\end{array}$ & $\begin{array}{l}\text { Closing a } \\
\text { Business }\end{array}$ & $\begin{array}{c}\text { Employing } \\
\text { Workers }\end{array}$ & $\begin{array}{l}\text { Protecting } \\
\text { Investors }\end{array}$ & $\begin{array}{c}\text { Registering } \\
\text { Property }\end{array}$ & $\begin{array}{l}\text { Getting } \\
\text { Credit }\end{array}$ & $\begin{array}{l}\text { Paying } \\
\text { Taxes }\end{array}$ & $\begin{array}{l}\text { Dealing with } \\
\text { Licenses }\end{array}$ \\
\hline South Africa & 29 & 43 & 57 & 67 & 65 & 87 & 9 & 69 & 33 & 74 & 45 \\
\hline Botswana & 48 & 77 & 93 & 89 & 22 & 62 & 118 & 34 & 13 & 67 & 136 \\
\hline Uganda & 107 & 71 & 107 & 161 & 44 & 8 & 60 & 166 & 159 & 43 & 110 \\
\hline Mozambique & 140 & 168 & 153 & 141 & 126 & 157 & 83 & 105 & 83 & 80 & 103 \\
\hline Tanzania & 142 & 65 & 127 & 67 & 105 & 143 & 99 & 157 & 117 & 113 & 172 \\
\hline Thailand & 18 & 44 & 28 & 103 & 38 & 46 & 33 & 18 & 33 & 57 & 3 \\
\hline Malaysia & 25 & 81 & 71 & 46 & 51 & 38 & 4 & 66 & 3 & 49 & 137 \\
\hline China & 93 & 63 & 128 & 38 & 75 & 78 & 83 & 21 & 101 & 168 & 153 \\
\hline Philippines & 126 & 59 & 108 & 63 & 147 & 118 & 151 & 98 & 101 & 106 & 113 \\
\hline India & 134 & 173 & 88 & 139 & 133 & 112 & 33 & 110 & 65 & 158 & 155 \\
\hline Indonesia & 135 & 145 & 161 & 60 & 136 & 140 & 60 & 120 & 83 & 133 & 131 \\
\hline Distance SADC $2 /$ & 111 & 125 & 123 & 120 & 104 & 95 & 74 & 71 & 70 & 69 & 58 \\
\hline Distance Asia and Pacific 2/, 3/ & 122 & 124 & 125 & 103 & 88 & 119 & 79 & 87 & 80 & 31 & 100 \\
\hline Change relative to 20053 / & 3 & 0 & -3 & 4 & 1 & 1 & 2 & 9 & 7 & 2 & -3 \\
\hline
\end{tabular}

Source : World Bank Doing Business Report, 2007.

1/ Out of 175 countries.

2/ Difference in ranks between Mozambique and highest ranked country in SADC, and Asia and Pacific (ASEAN 4, India, China), + = worse ranked.

$3 /$ Change in rank observed in Mozambique relative to previous year. (+ = worsening rank).

\section{Custom procedures also appear to be mostly ineffective according to mirror}

trade statistics. Mirror trade statistics for bordering countries show discrepancies with data reported by Mozambique. For example, the value of declared exports to Mozambique from South Africa exceeded the value of imports registered in Mozambique from South Africa (by about 29 percent); the figures also were higher for imports from Tanzania (by 37 percent) (Table 10). ${ }^{61}$ Mozambique reported twice as many imports to Malawi than Malawi reported exporting to Mozambique. In addition, the trade-weighted average tariff is lower than the simple average tariff, suggesting that a substantial amount of goods enter Mozambique duty free. It is interesting to note that countries with lower trade-weighted average tariffs, such as Angola, South Africa and Mauritius, have a lower discrepancy between their simple average and trade-weighted average tariffs (Table 4).

\footnotetext{
${ }^{60}$ See DTIS (2004).
}

${ }^{61}$ There is anecdotal evidence reported by Arndt (2005) on contraband and smuggling of goods on the borders of Mozambique. Goods are divided in small lots and smuggled through the borders. 


\begin{tabular}{lrrr} 
Table III.10. Mozambique: Mirror Statistics on Trade with Bordering Countries, 2004 \\
\hline & $\begin{array}{c}\text { Imports from bordering } \\
\text { countries as reported by } \\
\text { Mozambique }\end{array}$ & $\begin{array}{c}\text { Exports to Mozambique } \\
\text { as reported by } \\
\text { bordering countries }\end{array}$ & $\begin{array}{c}\text { Share not recorded at } \\
\text { Mozambique's border 1/ }\end{array}$ \\
\cline { 2 - 5 } Malawi & 29.4 & 17.2 & -0.71 \\
South Africa & 701.9 & 991.9 & 0.29 \\
Tanzania & 4.4 & 6.9 & 0.37 \\
Zimbabwe & 17 & 19.5 & 0.13 \\
\hline Source: WITS database. & & \\
1/ Numbers are represented in percent. &
\end{tabular}

\section{Summary}

71. Mozambique's external competitiveness gains have been concentrated in a few protected sectors; a weak business environment, meanwhile, has constrained the rest of the economy. Mozambique's competitiveness, measured as a share of exports in the world's exports has improved considerably in the past five years. However, export trends and volumes are dominated by megaprojects, which enjoy widespread protection, including tariff and tax exemptions and preferential access to EPZs. Though nonmegaproject businesses face tariff barriers that are among the least restrictive in the SSA region, as well as minimal nontariff barriers, the weak business environment continues to sap their competitiveness. Small- and medium-term enterprises, in particular, would benefit from improvements in areas such as customs procedures.

\section{Market Access}

72. Mozambique is in relatively good standing when it comes to market access. Mozambique has preferential market access to the United States (U.S.) under the African Growth and Opportunity Act, and to the European Union (E.U.) under the Cotonou Agreement and Everything but Arms initiative. In addition, under the Southern African Development Community (SADC) Trade Protocol, Mozambique's exports have preferential access to the lucrative South African market. Mozambique's bilateral trade patterns, particularly those with South Africa, largely reflect its market access (Table 11). Trade with South Africa absorbs about 16 percent of Mozambique's exports. Moreover, South Africa in 2005 accounted for more than 11 percent of FDI in Mozambique. The importance of FDI from South Africa is likely to continue following a relaxation of capital control on investments into SADC by South Africa's central bank.

Table III.11. Mozambique: Destination of Exports

\begin{tabular}{|c|c|c|}
\hline & $1991-01$ & $2002-05$ \\
\hline & \multicolumn{2}{|c|}{ Percent of total exports } \\
\hline Exports to World & 100.0 & 100.0 \\
\hline of which: exports to industrial countries & 57.5 & 66.2 \\
\hline Exports to United States & 7.9 & 1.5 \\
\hline Exports to European Union & 40.1 & 63.9 \\
\hline Exports to Africa & 29.4 & 23.1 \\
\hline Exports to South Africa & 16.2 & 15.8 \\
\hline
\end{tabular}

Source: IMF, Direction of Trade Statistics. 


\section{Revisiting Mozambique's market access strategy}

\section{Until recently SSA, including Mozambique, and ASEAN 4 countries followed} different market access strategies. While ASEAN 4 countries were liberalizing trade relations on a broad multilateral basis, following the most favored nation (MFN) principle underlying successive World Trade Organization trade rounds, SSA's strategy has typically been based on regional or bilateral preferential trading arrangements. ${ }^{62}$ In observing the MFN principle, countries levy tariffs or impose other restrictions without considering the origin of the goods or services imported, extending equal access to their markets to goods from all exporting countries. Regional or bilateral trading agreements, by contrast, only extend preferential access to goods and services from the countries participating in the agreement.

\section{The economic literature has usually regarded broad-based liberalization as the} best strategy. Vamvakidis (1998) and Yagci and Aldaz-Carroll (2004) are among several studies showing that economies trade more and grow faster after broad-based multilateral liberalization than after discriminatory liberalization. Other studies have argued that overlapping trade agreements - sometimes referred to as the "spaghetti-bowl of bilateral and regional trading agreements"-increases the complexity of the world trading system and might impose administrative costs on trade. As a result, Yagci and Aldaz-Carroll (2004) have estimated that SSA would stand to lose 0.7 percent of its GDP if all SSA countries negotiated bilateral free trade agreements (FTA) on manufacturing products with Australia, Canada, the EU, Japan, New Zealand, and the United States. Yang and Gupta (2005) argue that the costs could be even higher because (i) not all countries want to negotiate bilateral FTAs with African countries; (ii) complex rules of origin can be and have been used to restrict market access ${ }^{63}$ and (iii) SSA countries trying to negotiate and implement multiple bilateral FTAs face capacity constraints.

\section{Given the developments in Mozambique's traditional export sector, and taking} into account the other arguments made above, pursuing regional or bilateral agreements should be reconsidered as Mozambique's main market access strategy. Revisiting this strategy is also recommended in light of the expected negative impact on exports from preference erosion resulting from further trade liberalization, either through an increasing number of regional or bilateral FTAs or through agreement of further multilateral liberalization, such as the WTO Doha round. ${ }^{64}$ Trade policy in Mozambique has already

\footnotetext{
${ }^{62}$ ASEAN, the Association of South East Asian Nations, East Asia's first regional trade arrangement was established in 1967. See World Bank (1995) and Sarel (1996) for discussion of trade policy in ASEAN 4 countries.

${ }^{63}$ See Brenton, Flatters, and Kalenga (2005).

${ }^{64}$ Preference erosion is defined as a reduction in the tariff advantage enjoyed by a preferred beneficiary vis-à-vis its competitors. Preference erosion stems from multilateral liberalization and unilateral liberalization extended toward countries that do not include existing beneficiaries. See also discussion in Yang (2005).
} 
started to be geared in this direction. Mozambique has been more successful than most other SSA countries in simplifying its trading arrangements. It is a member of one regional trade agreement (SADC) and has thus been able to avoid the confusion associated with participating in overlapping trade agreements. ${ }^{65}$ This was one of the rationales for Mozambique's decision to suspend its participation in COMESA in 1995.

\section{Multilateral liberalization does not compromise poverty reduction efforts in} Mozambique. A recent study by Arndt (2005) considered the potential implications of trade liberalization scenarios on poverty in Mozambique. ${ }^{66}$ They used a general equilibrium model and household survey covering 2002-03 to evaluate the effects of price changes on commodities owing to trade liberalization on household consumption. The authors conclude that the Doha trade liberalization scenario has insignificant implications for poverty, particularly given the high value of domestic products consumption in the consumption distribution. $^{67}$

\section{However, market access decisions must consider potential revenue losses and} administrative capacity constraints associated with trade liberalization. ${ }^{68}$ For example, according to Alfieri et al (2006) Mozambique could loose 22 percent of its revenues on adoption of the Southern African Customs Unions (SACU), 28 percent of revenues by joining the SADC, 39 percent by achieving Most Favored Nation status, though the composition of those revenue losses differ by arrangement (Table 12). In addition, Mozambique could face administrative constraints, especially in joining SACU, which requires members to have a complex common external tariff of 38 bands and 216 rates. ${ }^{69}$

Table III.12. Mozambique: Actual and Estimated Revenue from International Trade, 2004

\begin{tabular}{|c|c|c|c|c|}
\hline & \multirow[t]{2}{*}{$\begin{array}{c}\text { Actual } \\
\text { Revenues } \\
\text { (Millions of Meticais) }\end{array}$} & \multicolumn{3}{|c|}{$\begin{array}{c}\text { Estimated Loss } \\
\text { (Percent of actual revenues) }\end{array}$} \\
\hline & & SADC & MFN & SACU \\
\hline Total Revenue from International Trade & 268 & 28 & 39 & 22 \\
\hline Duties and tariffs & 98 & 67 & 100 & 78 \\
\hline Excise & 22 & 10 & 7 & 27 \\
\hline VAT & 148 & 5 & 3 & 9 \\
\hline
\end{tabular}

\footnotetext{
${ }^{65}$ For more on this point see the Appendix, which estimates group integrity indexes and individual country commitments to RTAs for a number of SSA countries.

${ }^{66}$ See also Benito-Spinetto and Moll (2005).

${ }^{67}$ Mozambique's tariffs are zero in the Doha scenario.

${ }^{68}$ See IMF (2005), Arndt and Tarp (2005) and Arndt, Jones, and Tarp (2006).

${ }^{69}$ However, the rules of origin of SADC are more complicated than those of SACU.
} 


\section{Market access and business environment}

\section{Regardless of which market access strategy is pursued, success will depend on} the business environment in which firms operate. By improving the business environment, Mozambique would be able to better explore its current market access opportunities and increase its potential gains from any future liberalizations. A stronger business environment would also lead to more secure property rights, business friendly regulations, cheaper inputs and goods, the adoption of new technologies, and the emergence of more efficient firms, which combined would generate long-term gains in overall productivity. This is particularly important if Mozambique is to compete with SADC countries; these countries, which have the same preferential market access to the U.S. and E.U. markets and similar labor cost structures as Mozambique, tend to have stronger and less costly business environments (Table 9 and 13).

\begin{tabular}{|c|c|c|c|c|c|c|c|}
\hline & \multirow{2}{*}{$\begin{array}{l}\text { Wages per Hour } \\
\text { (U.S. Dollars) 1/ }\end{array}$} & \multirow{2}{*}{$\begin{array}{l}\text { Labor cost per shirt } \\
\text { (U.S. Dollars) } 1 /\end{array}$} & \multirow{2}{*}{$\begin{array}{l}\text { Daily Labor Productivity } \\
\text { (Shirts per worker) } 1 /\end{array}$} & \multirow{2}{*}{$\begin{array}{l}\text { Business Environment } \\
\text { (Distance to the top rank) }\end{array}$} & \multicolumn{3}{|c|}{ Preferential markert access } \\
\hline & & & & & AGOA & EBA & SADC \\
\hline Kenya & 0.38 & 0.18 & 15 & 0.47 & Yes & Yes & No \\
\hline Lesotho & $0.451 /$ & 0.19 & 18 & 0.65 & Yes & Yes & Yes \\
\hline Mauritius & 1.25 & n.a. & n.a. & n.a. & Yes & Yes & 1 \\
\hline Mozambique & n.a. & 0.16 & 11 & 0.79 & Yes & Yes & Yes \\
\hline Madagascar & 0.33 & 0.16 & 15 & 0.85 & Yes & Yes & No \\
\hline Malawi & n.a. & n.a. & n.a. & n.a. & 1 & & \\
\hline China & $0.783 /$ & 0.29 & 22 & n.a. & 0 & 0 & 0 \\
\hline India & 0.38 & 0.17 & 16 & n.a. & 0 & 0 & 0 \\
\hline Bangladesh & 0.39 & $0.084 /$ & n.a. & n.a. & 0 & 1 & 0 \\
\hline Sri Lanka & 0.48 & n.a. & n.a. & n.a. & 0 & 0 & 0 \\
\hline Pakistan & 0.41 & n.a. & n.a. & n.a. & 0 & 0 & 0 \\
\hline South Africa & 1.38 & 0.65 & 15 & 0.16 & Yes & Yes & No \\
\hline
\end{tabular}

Source : Cadot and Nasir (2001), The World Bank's Doing Business Indicators (2006).

1/ As estimated by Cadot and Nasir (2001).

\section{E. Conclusion: Policy Priorities and Lessons}

79. Mozambique's trade policy priority should be to make the business environment more friendly including by reducing the burden of trade regulations for small and medium-size enterprises. Mozambique has to some extent a less restrictive trade regime than most SSA countries. It already enjoys preferential access to profitable markets. On the other hand, Mozambique's business environment is weak even by regional standards with burdensome and ineffective trade regulations and custom procedures among its most binding constraints. As such, continuing to improve competitiveness through reforms to strengthen the business environment rather than utilizing scarce administrative resources in complex trade agreements would be Mozambique's main trade policy priority (Figure 3). In fact, a stronger business environment would also allow Mozambique to better exploit its current as well as prospective market access opportunities.

80. Further trade liberalization would still be important. Mozambique's tariffs in some low-level import categories are still high driving Mozambique's simple average tariff above regional standards. Moreover under a better regulatory environment, the impact of trade liberalization is expected to be higher as it allow emerging export-oriented firms to benefit from lower input costs and easier technology transfer. Looking ahead, it would be 
important that efforts to improve Mozambique's business environment be accompanied by further broad based MFN trade liberalization.

Figure III.3. Mozambique: Optimal Trade Policy Choices

\begin{tabular}{|c|c|}
\hline $\begin{array}{l}\text { Market Access } \\
\text { Competitiveness }\end{array}$ & Yes \\
\hline No & $\begin{array}{l}\text { Outcome (3): Trade is restricted. } \\
\text { - Preferential access to SADC, } \\
\text { E.U., and U.S. markets. } \\
\text { Weak business environment, } \\
\text { inc. burdensome and } \\
\text { ineffective custom procedures } \\
\text { Policy Priority : Address } \\
\text { competitiveness constraints in } \\
\text { order to utilize market access } \\
\text { opportunities }\end{array}$ \\
\hline
\end{tabular}

81. Mozambique's experience offers other SSA countries important lessons. Setting clear policy priorities focused on simplification of trade regulations and strengthening the business environment for small- and medium-size enterprises could improve trade in other SSA countries. Often, to offset difficult business environments and burdensome procedures, SSA countries use exemptions and special incentives that favor large businesses, leaving business environments for small- and medium-size businesses to remain difficult. Moreover, the trade policy decisions of African countries are often focused more on complex regional trade integration than on providing all economic agents with a fair business environment, a more pressing need in countries seeking to realize their trading potential. 


\section{Appendix. Regional Trade Agreements: Organizational Integrity}

This Appendix estimates hypothetical indexes for a country's commitment to RTAs and integrity of RTAs. It applies the following assumptions: (i) an individual country is 100 percent committed to the RTA if it is not a member of any other RTA; and (ii) the sum of members' commitments to an RTA defines the organizational integrity of this group. For example, if the RTA consists of individual members that do not belong to any other RTA, then the organizational integrity index is 100 percent. As shown in Table A, individual countries are members of up to four different RTAs, and the individual country's commitment index to RTAs varies from 25 to 50 percent, except for Mozambique, which has a 100 percent commitment to SADC. The organizational integrity of RTAs varies from 28 to 43 percent. The SADC is a more integrated RTA than all the other RTAs except for IGAD.

Table III.A. Africa: Indices of Individual Country Commitment and Group Integrity in Regional and Sub regional Economic Integration Groupings

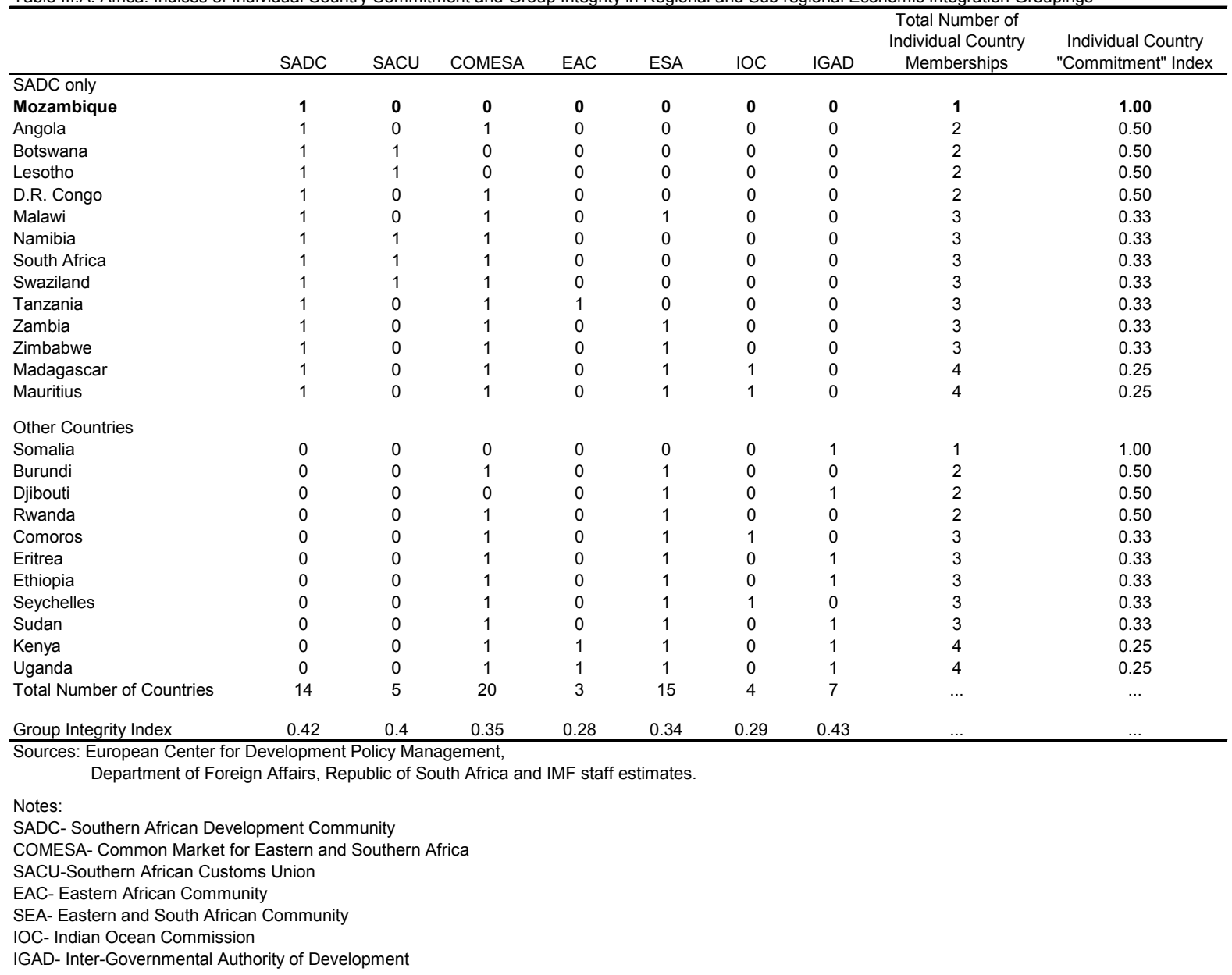




\section{References}

Alfieri, A., X. Cirera, and A. Rawlinson, 2006, "Estimating the Impact on Mozambique of Different Trade Policy regimes: SADC, SACU or MFN?," National Directorate of Studies and Policy Analysis Discussion Paper No. 29E.

Arndt, C., 2005, "The Doha Trade Round and Mozambique," The World Bank Policy

Research Working Paper No. 3717 (Washington, World Bank).

Arndt, C., and F. Tarp, 2005, "Trade Policy Reform and the Missing Revenue: An

Application to Mozambique," National Directorate of Studies and Policy Analysis

Discussion Paper No. 1E.

Arndt, C., S. Jones, and F. Tarp, 2006, “Aid and Development: Mozambique Case," National

Directorate of Studies and Policy Analysis Discussion Paper No. 27E.

Benito-Spinetto, M., and P. Moll, 2005, "Mozambique: Background Paper: Macroeconomic

Developments, Economic Growth and Consequences for Poverty," Background paper,

The World Bank Africa Region Working Paper Series (Washington: World Bank)

Berg, Andy, Jonathan D. Ostry, and Jeromin Zettelmeyer, 2006, "What Makes Growth

Sustained ?," unpublished manuscript.

Bernard, Andrew B., Stephen Redding, and Peter K. Schott, 2007 "Comparative Advantage

and Heterogeneous Firms," Review of Economic Studies, Vol. 74, pp. 31-66.

Bolaky, B., and C. Freund, 2004, "Trade, Regulations, and Growth,” World Bank Working

Paper WPS 42/55 (Washington: World Bank).

Brenton, P., F. Flatters, and P. Kalenga, 2005, "Rules of Origin and SADC: The Case for

Change in the Mid Term Review of the Trade Protocol," The World Bank Africa

Region Working Paper Series No. 83 (Washington: World Bank).

Cadot, O., and Nasir J., 2001, "Incentives and Obstacles to Growth: Lessons from

Manufacturing Case Studies in Madagascar," World Bank Regional Program on

Enterprise Development Discussion Paper no. 17.

Diagnostic Trade Integration Study (DTIS), 2004, "Removing Obstacles to Economic

Growth in Mozambique," Integrated Framework for Trade-Related Technical

Assistance to Least Developed Countries,

/www.integratedframework.org/countries/mozambique.htm.

Government of Mozambique, Ministry of Planning and Development (MPD), 2006,

Enterprise Development in Mozambique: Results Based on Manufacturing Surveys

Conducted in 2002 and 2006, Discussion Paper N 33E, October, National Directorate

of Studies and Policy Analysis (Maputo, Mozambique: National Directorate of Studies and Policy Analysis).

Grossman, Gene M., and Elhanan Helpman, 2002, Interest Groups and Trade Policy

(Princeton and Oxford, United Kingdom: Princeton University Press).

International Monetary Fund (IMF), 2002, "Market Access for Developing Country Exports-

Selected Issues," (Washington: International Monetary Fund).

, 2005, "Dealing with the Revenue Consequences of

Trade Reform," Background paper for review of Fund Work on Trade (Washington:

International Monetary Fund).

Johnson, Simon, Jonathan D. Ostry, and Arvind Subramanian, 2007, "The Prospects for Sustained Growth in Africa: Benchmarking the Constraints," IMF Working Paper No. 07/52 (Washington: International Monetary Fund). 
Porter, Michael. E., 1998, The Competitive Advantage of Nations (New York, NY : Free Press).

Sarel, Michael, 1996 "Growth in East Asia: What We Can and What We Cannot Infer," IMF Economic Issues No.1 (Washington: International Monetary Fund).

USAID, 2006, "Mozambique's Integration into Global Markets: Opportunities and Challenges."

Vamvakidis, A., 1998, "Regional Trade Arrangements versus Broad Liberalization: Which Path Leads to Faster Growth? Time Series Evidence" IMF Working Paper No. 98/40, (Washington: International Monetary Fund).

World Bank, 1995, The East Asian Miracle (Washington: World Bank).

Yagci, F., and E. Aldaz-Carroll, 2004, "Salient Features of Trade Performance in Eastern and Southern Africa, The World Bank Africa Region Working Paper Series No. 76 (Washington: World Bank).

Yang, Y., 2005, "Africa in the Doha Round: Dealing with Preference Erosion and Beyond," IMF Working Paper No. 05/8 (Washington: International Monetary Fund).

Yang, Y., and S. Gupta, 2005, "Regional Trade Arrangement in Africa: Past Performance and the Way Forward," IMF Working Paper No. 05/36 (Washington: International Monetary Fund). 